\title{
Tendências da Desigualdade Salarial para Coortes de Mulheres Brancas e Negras no Brasil
}

\author{
- Ana Maria Hermeto Camilo de Oliveira* - Eduardo luiz Gonçalves Rios-Neto**
}

\begin{abstract}
RESUMO
É feita uma análise das tendências da desigualdade salarial da força de trabalho feminina no Brasil, segundo a raça, durante as décadas de 1980 e 1990. Crescentes retornos de qualificação e crescente demanda por trabalho qualificado resultam em uma divergência do crescimento salarial entre os trabalhadores com alta e baixa qualificação. Este crescente hiato resulta em um aumento da desigualdade salarial por raça. Com o propósito de interpretar as tendências, são examinadas diferenças por raça nos padrões de casamento, fecundidade, arranjos domiciliares, níveis educacionais, participação na força de trabalho, níveis de qualificação, alocação ocupacional e salários, distinguindo entre medidas de período e coorte. São usados dados provenientes das PNADs 1987-1999 para analisar a importância de mudanças inter e intracoortes para mulheres brancas e negras. Funções salariais são estimadas a partir dos dados agregados da série temporal de cross sections, usando mínimos quadrados ordinários e regressões quantílicas.
\end{abstract}

\section{PALAVRAS-CHAVE}

desigualdade salarial, diferenciais por raça, regressão quantílica

\begin{abstract}
We analyze trends of wage inequality of the Brazilian female labor force, by race, during the 1980s and 1990s. Increasing returns to skills and increasing demand for skilled labor result in a divergence of wages growth between high and low skilled workers. This increasing gap results in an increase of wage inequality by race. In order to interpret trends, we take into account race differences in marriage patterns, fertility, household arrangements, educational levels, labor market participation, skill levels, occupational location and earnings, distinguishing between period and cohort measures. We use 1987-1999 Brazilian Household Sample Surveys data to examine the importance of within- and between-cohort changes for black and white women. Earnings functions are estimated from the pooled time-series of these cross-section data, using OLS and quantile regressions.
\end{abstract}

KEY WORDS

wage inequality, racial gap, quantile regression

JEL CLASSIFICATION

J3I, J7I

\footnotetext{
* Professora Adjunta do Departamento de Ciências Econômicas da UFMG e do CEDEPLAR/UFMG. Endereço: Rua Curitiba, 832, sala 9I4, 30I70-I20, Belo Horizonte, MG - Fone: (3I) 3279.9I54. E-mail: ahermeto@cedeplar.ufmg.br.

* Professor Titular do Departamento de Demografia do CEDEPLAR/UFMG. Endereço: Rua Curitiba, 832 - $9^{\circ}$ 303I5-430, Belo Horizonte, MG. Fone: (3I) 3279.9I00; Fax: (3I) 320I-3657. e-mail: eduardo@cedeplar.ufmg.br. (Recebido em setembro de 2003. Aceito para publicação em junho de 2005).
} 


\section{INTRODUÇÃO}

No final dos anos 1980, um século após a abolição da escravidão no Brasil, as condições dos brasileiros negros ainda se caracterizavam pela pobreza generalizada. Entre as mulheres negras, esta situação é ainda pior. Apesar da longa persistência desta situação, poucos autores reconhecem a discriminação como um fator que explica os diferenciais socioeconômicos por raça no Brasil. (Silva, 1980). O debate sobre a discriminação racial no mercado de trabalho brasileiro tem duas linhas, discutidas em vários estudos. (Hasenbalg, 1979; Silva, 1980; Oliveira et al. 1983; Lovell, 1989; Silva, Hasenbalg, 1992; Henriques, 2001). Alguns autores argumentam que brancos e negros têm as mesmas oportunidades de mobilidade econômica e social: por meio da educação e da renda. Seguindo este argumento, os diferenciais ocupacionais são interpretados como um resultado de um processo incompleto de mobilidade social. Neste sentido, diferenças na localização de classe, mais do que a discriminação, determinariam os diferenciais raciais. Outros autores afirmam que as diferenças ocupacionais e salariais por raça se devem à discriminação no mercado de trabalho. Níveis desiguais de educação, de acordo com este ponto de vista, seriam menos importantes na explicação da discriminação no mercado de trabalho. Evidências de que o nível de educação média dos negros jovens é atualmente mais elevado do que a dos seus pais ou avós sustentariam o argumento. E a despeito da mobilidade educacional, a discriminação salarial e ocupacional ainda existe entre negros e brancos no Brasil.

Um dos principais aspectos da economia brasileira é uma distribuição de salários e renda extremamente desigual. A proporção da renda apropriada pelas famílias $1 \%$ mais ricas (cerca de 1,6 milhões de pessoas) equivale à proporção apropriada pelas $50 \%$ mais pobres (cerca de 80 milhões de pessoas). Há uma extensa literatura discutindo as razões por trás do alto nível de desigualdade de renda no Brasil. As explicaçôes variam do contexto histórico do País à composição educacional da força de trabalho e fatores institucionais, tais como a segmentação e a discriminação no mercado de trabalho. Diferenciais salariais e ocupacionais entre brancos e negros constituem apenas um lado desta história de desigualdade de renda. Na medida em que afetam os homens, os diferenciais por raça foram objeto de alguns estudos. (Hasenbalg e Silva, 1988, 1998). Menos atenção foi direcionada às implicaçôes dos diferenciais por raça entre as mulheres. (Soares, 2000; Henriques, 2001). Explorar o impacto das mudanças que variam entre as mulheres brancas e negras pode ser elucidativo. Este interesse em resultados femininos relativos advém de uma preocupação de que as mulheres negras estão de várias formas em posições desfavorecidas no mercado de trabalho, na família e na sociedade como um todo. (Blau, 1998). ${ }^{1}$

1 A este respeito, vale mencionar que a mudança do peso dos estados conjugais, com a diminuição da proporção de cônjuges e o concomitante aumento da proporção de chefes dos domicílios, foi mais forte entre as mulheres negras. A proporção de mulheres chefes solteiras entre as negras está acima de $23 \%$ 
Enquanto intermediárias do impacto dos diferenciais nos indicadores acima sobre a desigualdade e a pobreza no Brasil, os diferenciais raciais no mercado de trabalho - salários e ocupações - entre as mulheres são o foco principal deste artigo. O hiato salarial entre as mulheres negras e brancas não somente não declinou, como realmente aumentou ao longo dos últimos 15 anos. Em média, em 1987 as mulheres negras recebiam $55 \%$ do que recebiam as brancas; em 1999 esta razão era de $52 \%$. Parte deste diferencial se deve à discriminação - salarial ou ocupacional - e não a diferenças de produtividade entre os grupos. O hiato salarial é somente a forma mais visível das diferenças no mercado de trabalho segundo a raça.

Com relação às tendências dos diferenciais por raça ao longo do tempo, estes podem ser pensados como dependentes dos efeitos de período, idade (experiência) e coortes. Os efeitos de período incluem mudanças no ambiente econômico, tais como fatores institucionais, taxas de inflação e desemprego, que afetam a força de trabalho como um todo e determinam os rendimentos individuais. Os efeitos de idade refletem o padrão de diferenças ao longo do ciclo de vida. A idade pode ser um determinante direto dos rendimentos por meio da experiência de trabalho e treinamento, que indica a aquisição de capital humano ou outras atividades que aumentem a produtividade percebida dos trabalhadores como uma função de sua experiência de trabalho, maturidade ou outros efeitos psicológicos, e pode ser um sinal usado pelos empregadores para estimar a produtividade. Os efeitos de coorte refletem mudanças permanentes na composição da população devido às características dos novos ingressos no mercado de trabalho, características tais como o tamanho da coorte, e o nível, qualidade e desigualdade de educação. Estes argumentos justificam a inclusão destas variáveis na função de rendimentos individuais a ser estimada, mas não a sua forma funcional. Não é possível estimar todos os coeficientes da equação sem restrições adicionais devido às interdependências conceituais entre as variáveis de idade, período e coorte. A estimação direta da equação por mínimos quadrados somente é possível com a imposição de restrições sobre seus parâmetros.

Neste artigo são exploradas as possibilidades das informações longitudinais dos microdados das repetidas cross sections da Pesquisa Nacional por Amostra de Domicílios $(\mathrm{PNAD}),{ }^{2}$ sendo construídos quase-painéis que permitem efetuar a análise de ciclo

em 1999 e 17\% entre as brancas. Isto é preocupante, tendo em vista os níveis educacionais mais baixos e as taxas de fecundidade mais elevadas das mulheres negras. Com relação a este ponto, no Brasil, as últimas décadas foram marcadas pelo processo de transição da fecundidade. A taxa de fecundidade total (TFT) se manteve praticamente constante entre 1940 e 1970 , declinando de $6,21 \%$ para $5,76 \%$ no período. Entre 1970 e 1980, a TFT declinou para 4,35\%, alcançando 2,70\% no período 1980/1991 e 2,11 no período 1991/2000. A divergência nas tendências de fecundidade entre os grupos raciais é notável. A TFT era aproximadamente a mesma em 1940 e declinou, em 1999, para 1,81\% entre as mulheres brancas e $2,41 \%$ entre as negras.

2 Conduzidas pelo IBGE, nos anos 1980 e 1990, exceto em 1991 e 1994. A amostra média anual é de 160.000 indivíduos e é representativa nacionalmente. A variável de raça foi investigada sistematicamente a partir de 1987. 
de vida e de coorte. ${ }^{3}$ Medidas de rendimentos têm fortes componentes de ciclo de vida relacionados à idade, mas os próprios perfis ascendem ao longo do tempo com o crescimento econômico à medida que cada geração torna-se mais bem-sucedida do que suas predecessoras. Neste caso, acompanhar diferentes coortes ${ }^{4}$ ao longo de sucessivas pesquisas permite decompor os componentes de geração dos de ciclo de vida nos perfis de rendimentos.

Nas seções que se seguem, um conjunto de indicadores de resultados no mercado de trabalho é considerado. Primeiro, são focalizados os salários e sua distribuição e tendências em algumas dimensões ocupacionais. Também são apresentados indicadores de capital humano e background familiar. Depois, uma metodologia para decomposição do hiato salarial por raça é apresentada. Finalmente, alguns modelos de determinação salarial são estimados e decompostos em seus componentes explicados e não explicados.

\section{TENDÊNCIAS DOS DIFERENCIAIS POR RAÇA ${ }^{5}$ NO MERCADO DE TRA- BALHO FEMININO BRASILEIRO}

Os diferenciais por raça no mercado de trabalho brasileiro têm persistido ao longo do tempo. Nesta seção é apresentado um conjunto básico de fatos sobre estes diferenciais entre as mulheres. São também mostradas diferenças em características pessoais, tais como o nível educacional, que tendem a estar relacionadas com o padrão de inserção no mercado de trabalho. O que mais interessa saber é se os diferenciais estão se ampliando ou estreitando ao longo do tempo. Além de permitir uma avaliação do progresso em direção a uma maior igualdade racial, o progresso relativo das mulheres negras é interessante porque os dados sobre as mulheres brancas fornecem uma referência útil. (Blau, 1998). As tendências absolutas dos indicadores também são

3 Estamos cientes de que a PNAD tem um desenho amostral que incorpora níveis de complexidade devido à estratificação, conglomeração e probabilidades desiguais de seleção. No entanto, incorporamos nos cálculos somente o fator de expansão de cada unidade amostral, já que, como mostram Leite e Silva (2002), as estimativas pontuais dos parâmetros são influenciadas pela ocorrência de pesos amostrais distintos, enquanto os efeitos de conglomeração e estratificação da amostra afetariam apenas as variâncias das estimativas dos coeficientes. Como os resultados dos próprios autores apontam, as diferenças são mínimas se incorporamos o plano amostral. Além disto, os pacotes estatísticos, em geral, não possuem rotinas adequadas para incorporar as complexidades do plano amostral.

4 Por exemplo, para identificar como os rendimentos individuais mudaram, acompanham-se os rendimentos médios da mesma coorte ao longo do tempo, considerando os membros da coorte que são aleatoriamente selecionados em cada período. Se uma coorte nasceu em 1962, tinha 25 anos de idade em 1987. Assim, usamos a pesquisa deste ano de 1987 para calcular o logaritmo dos rendimentos médios para todos os indivíduos de 25 anos, a pesquisa de 1988 para os rendimentos médios dos indivíduos de 26 anos, e assim por diante, até os rendimentos médios dos indivíduos de 37 anos em 1999.

5 É importante notar que o uso do termo "raça" é limitado. A divisão da variável em 2 grupos - negras e brancas - não é uma simplificação, e se justifica pela instabilidade da auto-identificação de negros e pardos ao longo do tempo. Se agregados em somente l categoria, estão menos sujeitos ao viés de reclassificação, que não deve ser subestimado. (Silva, 1980; Wood, 1991). 
importantes. Por exemplo, é instrutivo saber não meramente que o hiato salarial por raça está aumentando, mas também a magnitude dos decréscimos dos salários reais para as mulheres negras.

As últimas décadas foram um período de significativas transformações da inserção no mercado de trabalho e da estrutura familiar das mulheres no Brasil. A participação feminina na força de trabalho aumentou de forma sustentada desde 1950. Dados censitários indicam uma elevação da taxa de participação de 13,6\% em 1950 para $26,9 \%$ em 1980. Mais recentemente, a taxa de participação das mulheres urbanas aumentou de 30,3\% em 1976 para 45,5\% em 1999. Entre as mulheres brancas, houve um aumento de 39,3\% em 1987 para 45,8\% em 1999, e entre as mulheres negras, o crescimento desta taxa ficou defasado, aumentando de $40,5 \%$ para $45,1 \%$ no período. O aumento da participação na força de trabalho observado nos anos 1980 e 1990 foi acompanhado por uma mudança em seu perfil etário de período, o que é compatível com um aumento da taxa de participação das mulheres casadas e mães (Gráfico l). Em 1987, as taxas de participação das mulheres negras eram mais elevadas em quase todos os grupos etários, sendo que o diferencial aumentava com a idade. Em 1999, o diferencial de participação por idade entre as raças é mínimo.

GRÁFICO 1 - TAXAS DE PARTICIPAÇÃO FEMININA NA FORÇA DE TRABALHO, POR RAÇA E IDADE, BRASIL URBANO, 1987-1999

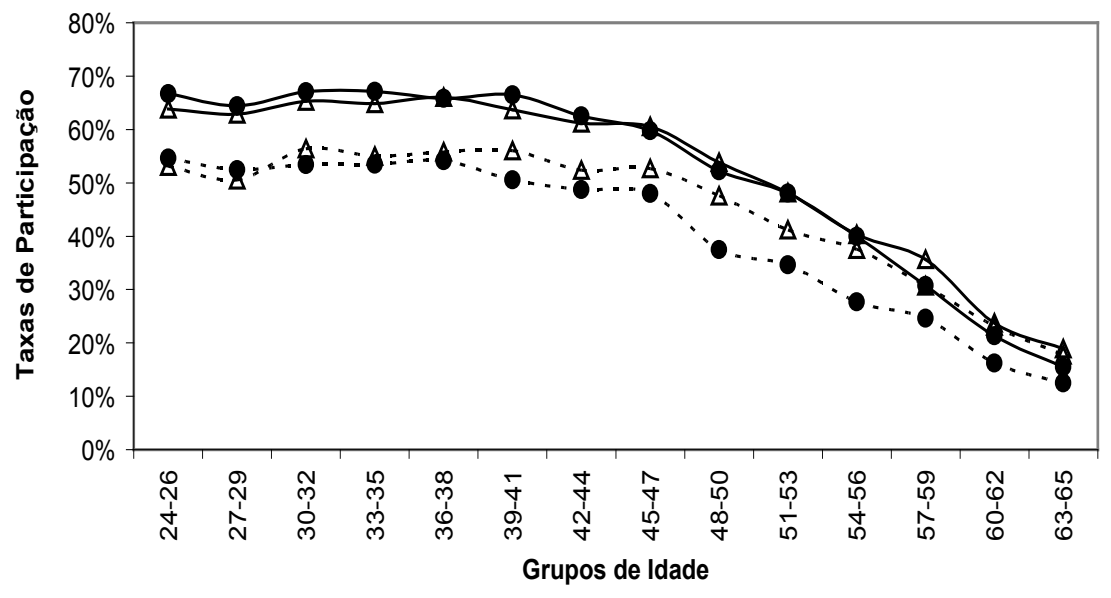

- • - Brancas - $1987 \longrightarrow$ Brancas - $1999 \cdots \Delta-\cdots$ Negras - $1987 \longrightarrow \Delta$ Negras - 1999

Fonte: Elaboração própria, a partir dos microdados da PNAD, IBGE, 1987-1999.

Os dados utilizados neste artigo foram obtidos das PNADs de 1987 a 1999. Esta base de dados foi usada porque é constituída por uma amostra grande, representativa 
em nível nacional, permitindo considerável desagregação por subgrupos. Embora estas pesquisas cross section selecionem diferentes domić́lios a cada ano, tal que não há possibilidade de acompanhar os mesmos indivíduos ao longo do tempo, é possível seguir grupos de uma pesquisa para outra. (Deaton, 1997). Neste caso, o interesse é em seguir as coortes de mulheres ao longo do tempo, sendo as coortes definidas pela data de nascimento. É possível usar estas pesquisas repetidas para seguir cada coorte ao longo do tempo ${ }^{6}$ olhando para os membros da coorte que foram selecionados aleatoriamente em cada ano. A amostra utilizada neste artigo se limita às mulheres brancas e negras com idade entre 24 e 65 anos, em áreas urbanas, que soma 200.000 observações acumuladas ao longo do período.

\subsection{Salários}

O Gráfico 2 mostra os salários médios por hora das mulheres brancas e negras, entre 1987 e 1999. Estes dados indicam que as mulheres brancas recebem, ao longo de todo o período, quase o dobro do que recebem as mulheres negras. As tendências salariais revelam que embora os salários tenham aumentado a partir de 1993 para ambos os grupos de mulheres, as diferenças por raça persistem. Os salários das mulheres negras nunca se equipararam aos das mulheres brancas, ou seja, não houve uma melhoria relativa. Flutuações visíveis ao longo do tempo, similares para os grupos, sugerem que efeitos de período devem ser levados em consideração.

\section{GRÁFICO 2 - SALÁRIOS/HORA REAIS MÉDIOS DAS MULHERES, POR RAÇA, BRASIL URBANO, 1987-1999}

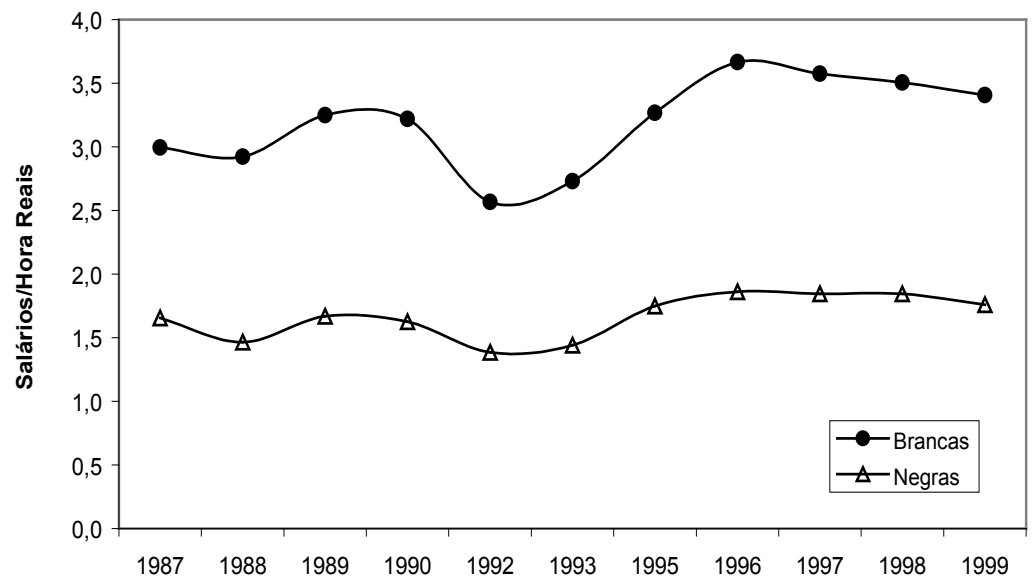

Fonte: Elaboração própria, a partir dos microdados da PNAD, IBGE, 1987-1999.

6 Assumindo que não há diferenças por raça nos padrões de mortalidade e migração, que poderiam enviesar a composição das coortes. 


\section{GRÁFICO 3 - HIATO SALARIAL ENTRE AS MULHERES NEGRAS E BRANCAS, BRASIL URBANO, 1987-1999}

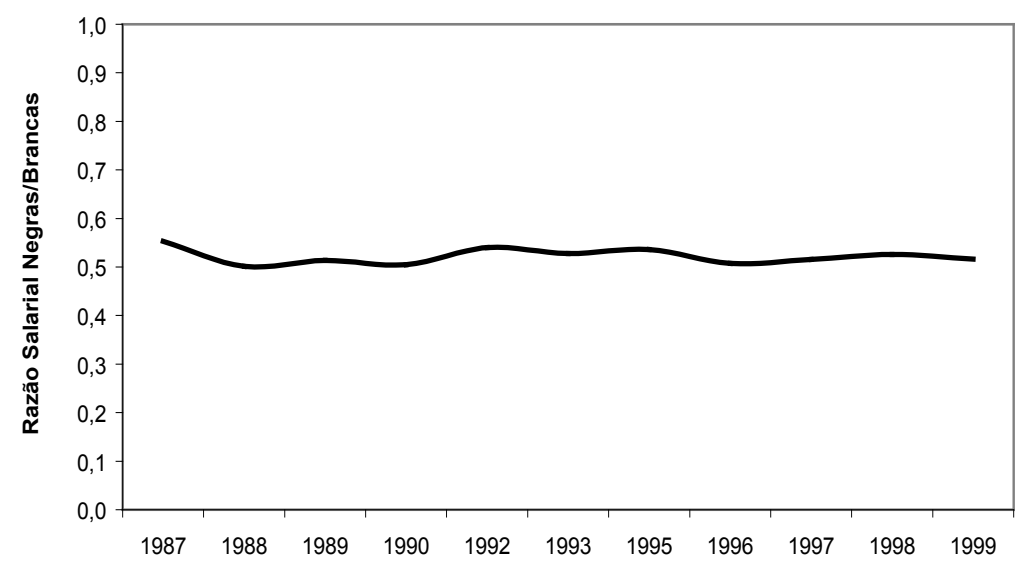

Fonte: Elaboração própria, a partir dos microdados da PNAD, IBGE, 1987-1999.

Análises de hiatos salariais tipicamente enfatizam estatísticas que resumem o diferencial entre os salários das mulheres brancas e negras, como, por exemplo, as razões entre os salários médios mostradas no Gráfico 3. Os valores para as mulheres negras são os numeradores, tal que as razões representam a fração do que a mulher negra média recebe em relação à mulher branca média. De forma geral, o hiato por raça aumentou ligeiramente ao longo dos últimos 15 anos, tendo em vista que a razão entre as médias dos salários das mulheres negras e brancas diminuiu de 0,553 em 1987 para 0,517 em 1999. A persistência do hiato salarial significa que as mulheres brancas enquanto grupo se beneficiaram mais do que as mulheres negras em termos do crescimento do salário real. Os salários reais das mulheres brancas aumentaram 13,7\% entre 1987 e 1999; em contraste, os salários reais das mulheres negras aumentaram somente 6,2\% ao longo deste período.

Com o objetivo de proceder a uma análise de coorte, os dados obtidos a partir das múltiplas pesquisas cross section foram sintetizados em tabelas de idade x período: cada célula é a média observada para cada grupo etário em um ano específico. Os intervalos dos grupos etários (I) são iguais aos intervalos entre os períodos (P): três anos. ${ }^{7}$ Desta forma, as diagonais da tabela correspondem às coortes de nascimento. ${ }^{8}$ A Tabela 1 mostra os salários médios para as mulheres brancas e negras, por idade e coorte, entre 1987 e 1999.

7 A definição destes intervalos foi arbitrária, em razão de maximizar as informações disponíveis, entre 1987 e 1999.

8 O número de diagonais - coortes $(\mathrm{C})$ - equivalem ao número de grupos etários (I) somado ao número de períodos $(\mathrm{P})$ menos 1 , ou seja, $\mathrm{C}=\mathrm{I}+\mathrm{P}-1$. 
TABELA 1 - SALÁRIOS/HORA REAIS DAS MULHERES POR RAÇA E GRUPO ETÁRIO (COORTE), BRASIL URBANO, 1987-1999

\begin{tabular}{|c|c|c|c|c|c|c|c|c|c|c|}
\hline & \multicolumn{5}{|c|}{ Brancas } & \multicolumn{5}{|c|}{ Negras } \\
\hline & 1987 & 1990 & 1993 & 1996 & 1999 & 1987 & 1990 & 1993 & 1996 & 1999 \\
\hline $24-26$ & 1,371 & 1,345 & 1,185 & 1,682 & 1,416 & 0,921 & 0,913 & 0,741 & 0,983 & 0,956 \\
\hline $27-29$ & 2,083 & 1,947 & 1,684 & 2,069 & 1,960 & 1,386 & 1,366 & 1,021 & 1,300 & 1,276 \\
\hline $30-32$ & 2,651 & 2,881 & 2,257 & 2,839 & 2,562 & 1,627 & 1,667 & 1,405 & 1,701 & 1,529 \\
\hline 33-35 & 3,539 & 3,456 & 2,918 & 3,350 & 3,176 & 2,022 & 1,829 & 1,560 & 1,845 & 1,827 \\
\hline $36-38$ & 4,012 & 4,003 & 3,157 & 3,903 & 3,472 & 2,200 & 1,989 & 1,875 & 2,146 & 1,859 \\
\hline $39-41$ & 4,066 & 3,956 & 3,325 & 4,349 & 3,888 & 2,333 & 2,215 & 1,954 & 2,181 & 2,140 \\
\hline $42-44$ & 3,973 & 4,373 & 3,334 & 5,003 & 4,026 & 2,415 & 1,948 & 1,880 & 2,243 & 2,125 \\
\hline $45-47$ & 4,073 & 4,320 & 3,571 & 4,944 & 4,093 & 2,349 & 2,041 & 1,860 & 2,291 & 2,062 \\
\hline $48-50$ & 3,643 & 4,484 & 3,766 & 4,884 & 4,453 & 2,105 & 2,105 & 1,775 & 2,456 & 2,217 \\
\hline $51-53$ & 3,532 & 4,076 & 3,234 & 4,284 & 4,389 & 1,861 & 1,966 & 1,633 & 2,427 & 2,109 \\
\hline $54-56$ & 3,443 & 4,236 & 3,324 & 4,016 & 4,129 & 1,826 & 1,778 & 1,704 & 2,358 & 2,100 \\
\hline $57-59$ & 3,095 & 3,359 & 2,985 & 3,749 & 4,167 & 1,739 & 1,810 & 1,394 & 2,185 & 2,103 \\
\hline $60-62$ & 3,061 & 3,240 & 2,854 & 3,429 & 3,744 & 1,263 & 1,476 & 1,221 & 1,853 & 1,994 \\
\hline 63-65 & 3,296 & 2,798 & 3,204 & 3,310 & 4,095 & 1,303 & 1,491 & 1,161 & 1,813 & 1,679 \\
\hline
\end{tabular}

Fonte: Elaboração própria, a partir dos microdados da PNAD, IBGE, 1987-1999.

A interpretação dos componentes desta tabela é ambígua, porque a coorte está associada às outras dimensões temporais. Se, para uma dada coorte, os salários médios aumentam a cada ano, isto sugere um efeito de período; contudo, simultaneamente, os salários estão aumentando para cada grupo etário, o que sugere um efeito de idade. Os dados são os mesmos, mas a interpretação é diferente, e não é possível verificar efeitos de coorte com base nestas informações. Dado que está evidente que há efeitos de idade (ciclo de vida) sobre os salários médios, as diferenças intracoortes confundem efeitos de idade e período, e as diferenças intercoortes confundem efeitos de idade e coorte. É possível que o padrão dos salários seja completamente explicado por efeitos de idade e período e que não haja efeitos de coorte, tanto para as mulheres brancas quanto para as negras. A Tabela 1 e o Gráfico 4 mostram que as mulheres mais velhas em ambos os grupos foram mais bem-sucedidas do que as mulheres mais jovens em termos do crescimento do salário real acumuladamente entre 1987 e 1999. Para cada grupo etário, as mudanças para as mulheres brancas foram mais favoráveis do que para os grupos correspondentes de mulheres negras. ${ }^{9}$

As informações contidas nas diagonais da Tabela 1 correspondem aos salários médios para coortes de mulheres brancas e negras, específicos por grupo etário. Estes dados em intervalos trienais permitem comparações entre frações de coortes de nascimentos

9 Há duas exceções: para o grupo etário 24-26 anos, o aumento salarial é maior para as mulheres negras; e, para o grupo etário 33-35 anos, os aumentos salariais foram idênticos para os grupos. 
entre 1934 e 1975. Os padrões mostrados, de melhor situação das mulheres brancas, confirmam as medidas de diferenciais salariais ao longo dos períodos mostradas anteriormente. Efeitos de idade são notados tanto para as mulheres brancas quanto para as negras, e são particularmente claros para as brancas.

GRÁFICO 4 - SALÁRIOS/HORA REAIS DAS MULHERES, POR RAÇA E GRUPO ETÁRIO, BRASIL URBANO, 1987-1999

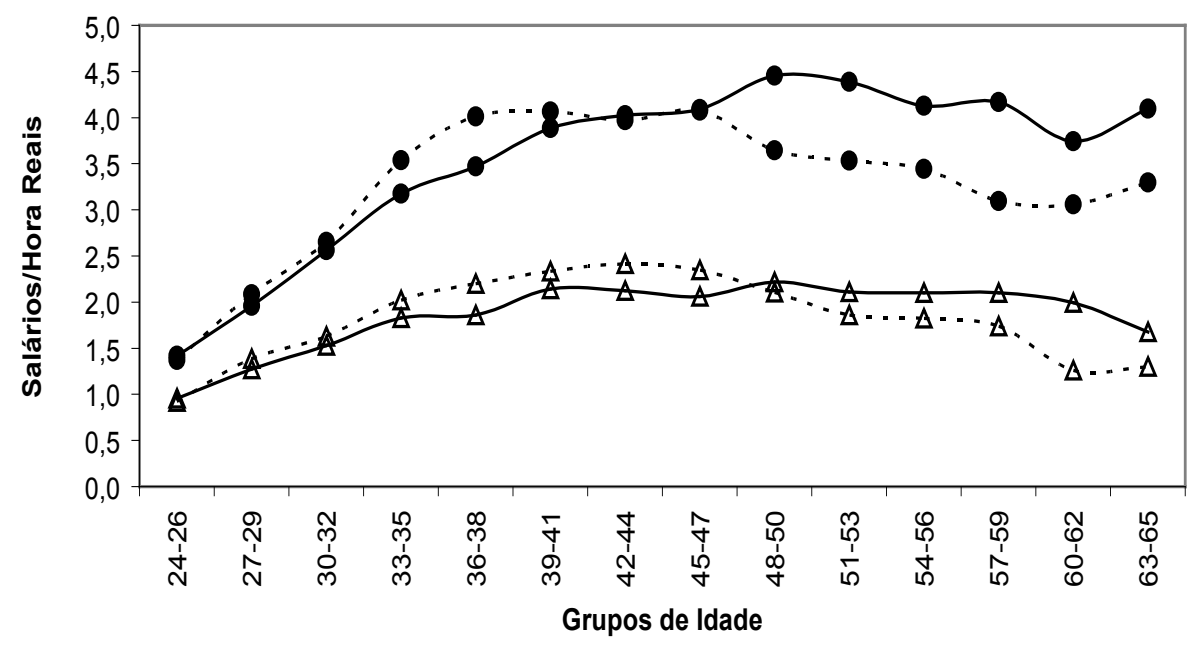

$\cdots$ - Brancas - $1987 \longrightarrow$ Brancas - $1999 \cdots \Delta \cdots$ Negras - $1987 \longrightarrow \Delta-$ Negras -1999

Fonte: Elaboração própria, a partir dos microdados da PNAD, IBGE, 1987-1999.

Razões salariais por raça para os grupos etários separados são mostradas na Tabela 2. As mulheres negras de todas as idades não conseguiram estreitar o hiato relativo às mulheres brancas de mesma idade. Os hiatos permanecem maiores nos grupos etários mais avançados e menores nos mais jovens. Olhando para as linhas para verificar mudanças intercoortes, a grande maioria dos grupos etários apresenta um aumento do hiato ao longo do tempo. Olhando para as diagonais para verificar mudanças intracoortes, todas as coortes parecem apresentar o mesmo padrão geral de crescente hiato ao longo do ciclo de vida. Não é óbvia a distinção de diferenças entre os padrões das coortes.

O Gráfico 5 ilustra as mudanças intercoortes entre 1987 e 1999. Parece claro que o hiato aumentou para os grupos de idades entre 36 e 56 anos, neste período. Isto sugere salários relativos declinantes para as mulheres negras entre as coortes. 
Adicionalmente, salários relativos declinantes para as mulheres negras também são observados dentro das coortes.

TABELA 2 - HIATO SALARIAL ENTRE AS MULHERES NEGRAS E BRANCAS, POR GRUPO ETÁRIO (COORTE), BRASIL URBANO, 1987-1999

\begin{tabular}{cccccc}
\hline & 1987 & 1990 & 1993 & 1996 & 1999 \\
\hline $24-26$ & $\mathbf{0 , 6 7 2}$ & 0,678 & 0,625 & 0,585 & 0,675 \\
$27-29$ & 0,666 & $\mathbf{0 , 7 0 1}$ & 0,606 & 0,628 & 0,651 \\
$30-32$ & 0,614 & 0,579 & $\mathbf{0 , 6 2 3}$ & 0,599 & 0,597 \\
$33-35$ & 0,571 & 0,529 & 0,534 & $\mathbf{0 , 5 5 1}$ & 0,575 \\
$36-38$ & 0,548 & 0,497 & 0,594 & 0,550 & $\mathbf{0 , 5 3 5}$ \\
$39-41$ & 0,574 & 0,560 & 0,588 & 0,501 & 0,550 \\
$42-44$ & 0,608 & 0,446 & 0,564 & 0,448 & 0,528 \\
$45-47$ & 0,577 & 0,472 & 0,521 & 0,463 & 0,504 \\
$48-50$ & 0,578 & 0,469 & 0,471 & 0,503 & 0,498 \\
$51-53$ & $\mathbf{0 , 5 2 7}$ & 0,482 & 0,505 & 0,566 & 0,481 \\
$54-56$ & 0,530 & $\mathbf{0 , 4 2 0}$ & 0,513 & 0,587 & 0,509 \\
$57-59$ & 0,562 & 0,539 & $\mathbf{0 , 4 6 7}$ & 0,583 & 0,505 \\
$60-62$ & 0,413 & 0,456 & 0,428 & $\mathbf{0 , 5 4 0}$ & 0,533 \\
$63-65$ & 0,395 & 0,533 & 0,362 & 0,548 & $\mathbf{0 , 4 1 0}$ \\
\hline
\end{tabular}

Fonte: Elaboração própria, a partir dos microdados da PNAD, IBGE, 1987-1999.

GRÁFICO 5 - HIATO SALARIAL ENTRE AS MULHERES NEGRAS E BRANCAS, POR IDADE, BRASIL URBANO, 1987-1999

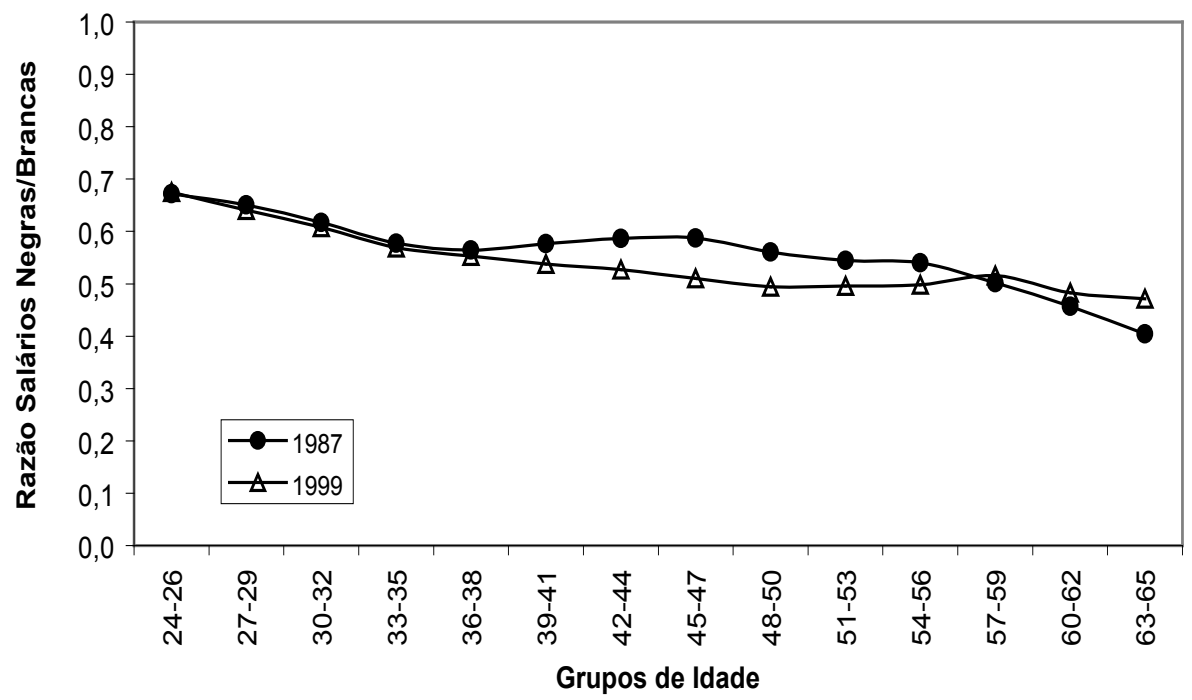

Fonte: Elaboração própria, a partir dos microdados da PNAD, IBGE, 1987-1999. 
Desta forma, salários relativos declinantes para as mulheres negras foram observados tanto dentro quanto entre as coortes. A Tabela 3 pretende contribuir para a discussão deste ponto, comparando as mudanças nos salários reais inter e intracoortes segundo a raça. Seria de se esperar que a comparação das mudanças intra e intercoortes dos salários reais entre as mulheres negras e brancas revelasse diferenças consideráveis nas mudanças salariais intracoortes segundo a raça, mas relativamente pouca diferença nas mudanças intercoortes. Isto porque as diferenças salariais entre as mulheres brancas e negras são mais acentuadas ao longo do ciclo de vida para todas as coortes do que entre as próprias coortes. Sinais negativos nas colunas das diferenças são indicativos de que a mudança para as mulheres brancas é algebricamente maior (mais positiva ou menos negativa) do que para as negras.

Olhando para os resultados mostrados na Tabela 3, as comparações intra e intercoortes indicam um crescente hiato entre os grupos. Os resultados para as mulheres brancas são mais fortes neste sentido, indicando que as mudanças intracoortes são maiores do que as correspondentes mudanças intercoortes. É possível observar que as mudanças intracoortes exibem um padrão inverso de mudanças em relação às mudanças intercoortes; assim, há uma forte evidência de que as tendências específicas por idade são mais relevantes do que as tendências de coorte. A predominância de sinais negativos nas colunas das diferenças corrobora a pior situação das mulheres negras. Todavia, a situação parece melhor para as coortes mais jovens, como indicado pelos menores valores negativos das diferenças intercoortes para os grupos de idade entre 27 e 41 anos, e até por um valor positivo para o grupo de 24 a 26 anos de idade.

TABELA 3 - DIFERENÇAS ENTRE AS MUDANÇAS INTRA E INTERCOORTES DOS SALÁRIOS REAIS, SEGUNDO A RAÇA DAS MULHERES, BRASIL URBANO, 1987-1999

\begin{tabular}{|c|c|c|c|c|c|c|}
\hline \multirow{2}{*}{$\begin{array}{l}\text { Grupo Etário } \\
\text { em } 1987\end{array}$} & \multicolumn{2}{|c|}{ Intracoortes } & \multicolumn{2}{|c|}{ Intercoortes } & \multicolumn{2}{|c|}{ Diferença Negras-Brancas } \\
\hline & Brancas & Negras & Brancas & Negras & Intracoortes & Intercoortes \\
\hline $24-26$ & 2,53 & 2,02 & 1,03 & 1,04 & $-51,40 \%$ & $0,52 \%$ \\
\hline $27-29$ & 1,87 & 1,54 & 0,94 & 0,92 & $-32,25 \%$ & $-2,03 \%$ \\
\hline $30-32$ & 1,52 & 1,31 & 0,97 & 0,94 & $-21,26 \%$ & $-2,67 \%$ \\
\hline $33-35$ & 1,16 & 1,02 & 0,90 & 0,90 & $-13,68 \%$ & $0,61 \%$ \\
\hline $36-38$ & 1,11 & 1,01 & 0,87 & 0,85 & $-10,22 \%$ & $-2,04 \%$ \\
\hline $39-41$ & 1,08 & 0,90 & 0,96 & 0,92 & $-17,55 \%$ & $-3,89 \%$ \\
\hline $42-44$ & 1,04 & 0,87 & 1,01 & 0,88 & $-16,97 \%$ & $-13,34 \%$ \\
\hline $45-47$ & 1,02 & 0,90 & 1,00 & 0,88 & $-12,78 \%$ & $-12,71 \%$ \\
\hline $48-50$ & 1,03 & 0,95 & 1,22 & 1,05 & $-8,05 \%$ & $-16,91 \%$ \\
\hline $51-53$ & 1,16 & 0,90 & 1,24 & 1,13 & $-25,72 \%$ & $-10,94 \%$ \\
\hline
\end{tabular}

Fonte: Elaboração própria, a partir dos microdados da PNAD, IBGE, 1987-1999. 


\subsection{Distribuição Salarial}

O hiato salarial médio entre as mulheres brancas e negras permaneceu estável ao longo das décadas de 1980 e 1990. Um retrato mais abrangente emerge se a distribuição completa dos salários das mulheres negras relativa à das mulheres brancas é analisada. Isto é apresentado como uma série de décimos relativos na Tabela 4. A distribuição relativa é essencialmente uma razão de densidade rescalonada: a razão entre a probabilidade das mulheres negras e brancas de estarem situadas em cada nível da escala de salários. (Handcock and Morris, 1999). Na prática, ao salário de cada mulher negra é atribuída a posição em que estaria na distribuição salarial das mulheres brancas naquele ano. Cada célula representa a fração de mulheres negras situada em cada décimo da escala de salários das mulheres brancas ao longo do tempo. Se as distribuições salariais das mulheres brancas e negras fossem iguais, os décimos relativos assumiriam um valor uniforme de $10 \%$ ao longo da escala de salários, porque $10 \%$ das mulheres negras estariam situadas em cada décimo das mulheres brancas. Neste caso, a distribuição relativa está longe de ser uniforme: a maior parte da massa na distribuição das mulheres negras está concentrada no extremo inferior da distribuição das mulheres brancas, e isto muda muito pouco entre 1987 e 1999. Um quarto das mulheres negras está no décimo inferior da distribuição das mulheres brancas, e mais de $70 \%$ ganhavam menos do que a mulher branca mediana. A persistente ausência de mulheres negras no extremo superior da distribuição salarial das mulheres brancas é igualmente impressionante: menos de $3 \%$ das mulheres negras se situa no décimo superior. A distribuição relativa torna claro que não houve uma reversão da desigualdade racial entre as mulheres ao longo dos anos.

Refinando a análise, as tendências dos salários nos percentis da distribuição de salários são analisadas. Esta análise permite verificar, dado que uma mulher está situada em um percentil da distribuição, quanto seus rendimentos aumentaram (razão 1999/1987). O Gráfico 6 mostra o crescimento dos salários das mulheres brancas e negras em cada percentil da distribuição entre 1987 e 1999. As mulheres de ambos os grupos nos percentis inferiores (até cerca do $25^{\circ}$ ) tiveram um ganho real maior do que o das mulheres nos percentis intermediários e superiores, as quais apresentaram uma pequena variação. Isto é importante para a diminuição da desigualdade dentro de cada grupo racial. É possível visualizar que os salários por percentil aumentaram mais para as mulheres negras do que para as brancas, sobretudo nos percentis inferiores. Por outro lado, nos dez percentis superiores, os aumentos dos salários das mulheres negras foram bem menores. ${ }^{10}$ Isto leva a um padrão de convergência entre as mulheres negras, mas mantém a divergência entre as raças. $\mathrm{O}$ Gráfico 7 mostra as razões salariais entre as mulheres negras e brancas para 1987 e 1999. Confirma-se

$10 \mathrm{Na}$ média do decil superior de cada distribuição, o ganho relativo das mulheres brancas foi de $6 \%$ entre 1987 e 1999, enquanto para as mulheres negras a perda relativa foi de $-2 \%$. 
que as mulheres brancas tiveram ganhos relativos mais baixos ao longo do período nos percentis inferiores, mas mais elevados em outros pontos da distribuição: do $25^{\circ}$ ao $40^{\circ}$ e acima do $90^{\circ}$ percentil. Isto se reflete em uma diminuição do hiato salarial nos percentis inferiores, uma flutuação nos intermediários, e um aumento do hiato nos percentis superiores.

TABELA 4 - DISTRIBUIÇÃO RELATIVA DOS SALÁRIOS DAS MULHERES NEGRAS E BRANCAS, BRASIL URBANO, 1987-1999

\begin{tabular}{ccc}
\hline Décimos & 1987 & 1999 \\
\hline 1 & $23,4 \%$ & $25,0 \%$ \\
2 & $15,7 \%$ & $15,5 \%$ \\
3 & $12,7 \%$ & $12,7 \%$ \\
4 & $11,6 \%$ & $10,1 \%$ \\
5 & $9,8 \%$ & $9,2 \%$ \\
6 & $7,6 \%$ & $8,3 \%$ \\
7 & $7,8 \%$ & $6,9 \%$ \\
8 & $4,3 \%$ & $6,3 \%$ \\
9 & $4,0 \%$ & $3,6 \%$ \\
10 & $2,9 \%$ & $2,4 \%$ \\
\hline
\end{tabular}

Fonte: Elaboração própria, a partir dos microdados da PNAD, IBGE, 1987-1999.

GRÁFICO 6 - VARIAÇÃO 1999/1987 DOS SALÁRIOS/HORA REAIS DAS MULHERES AO LONGO DAS DISTRIBUIÇÕES SALARIAIS POR RAÇA, BRASIL URBANO

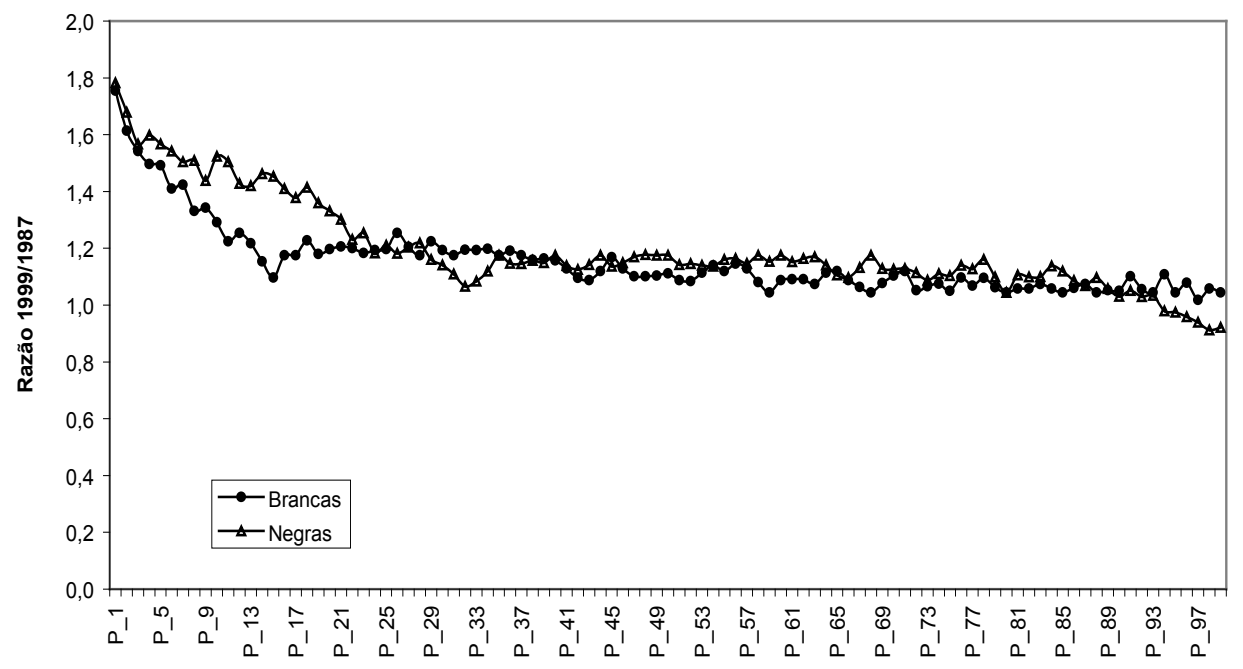

Fonte: Elaboração própria, a partir dos microdados da PNAD, IBGE, 1987-1999. 


\section{GRÁFICO 7 - HIATO SALARIAL ENTRE AS MULHERES NEGRAS E BRANCAS, AO LONGO DA DISTRIBUIÇÃO SALARIAL, BRASIL URBANO, 1987-1999}

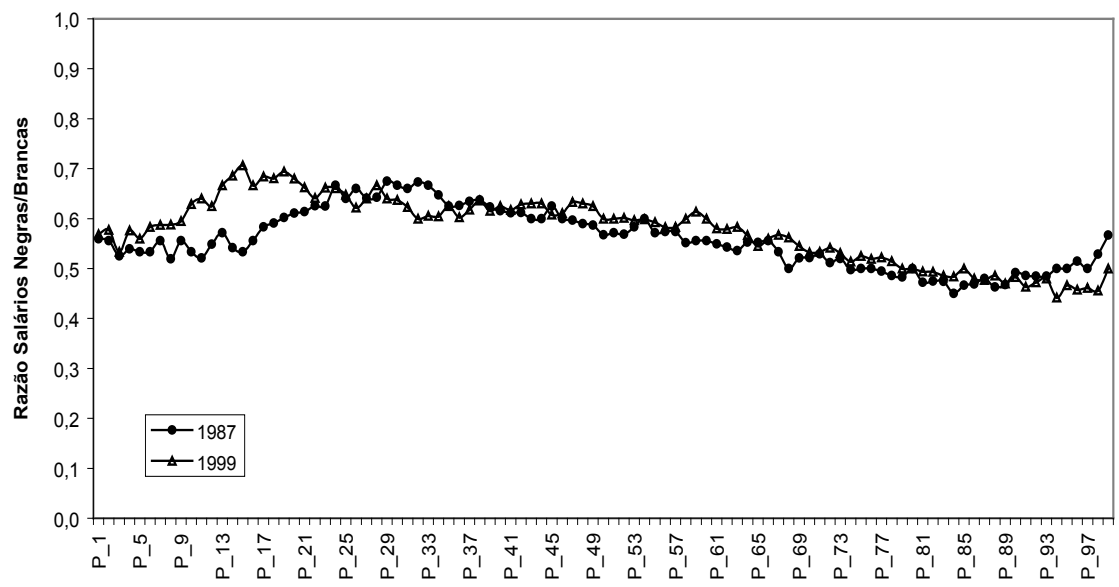

Fonte: Elaboração própria, a partir dos microdados da PNAD, IBGE, 1987-1999.

Os resultados acima indicam que as tendências da desigualdade salarial foram mais positivas entre as mulheres negras. Eles podem ser adicionalmente analisados usando uma medida resumida da desigualdade, a razão $90^{\circ} / 10^{\circ}$, que é a razão entre os salários médios das mulheres no $90^{\circ}$ percentil da distribuição salarial e os das mulheres no $10^{\circ}$ percentil, o que pode ser visto no Gráfico 8 .

GRÁFICO 8 - DESIGUALDADE SALARIAL $\left(90^{\circ} / 10^{\circ}\right)$ ENTRE AS MULHERES, SEGUNDO A RAÇA, BRASIL URBANO, 1987-1999

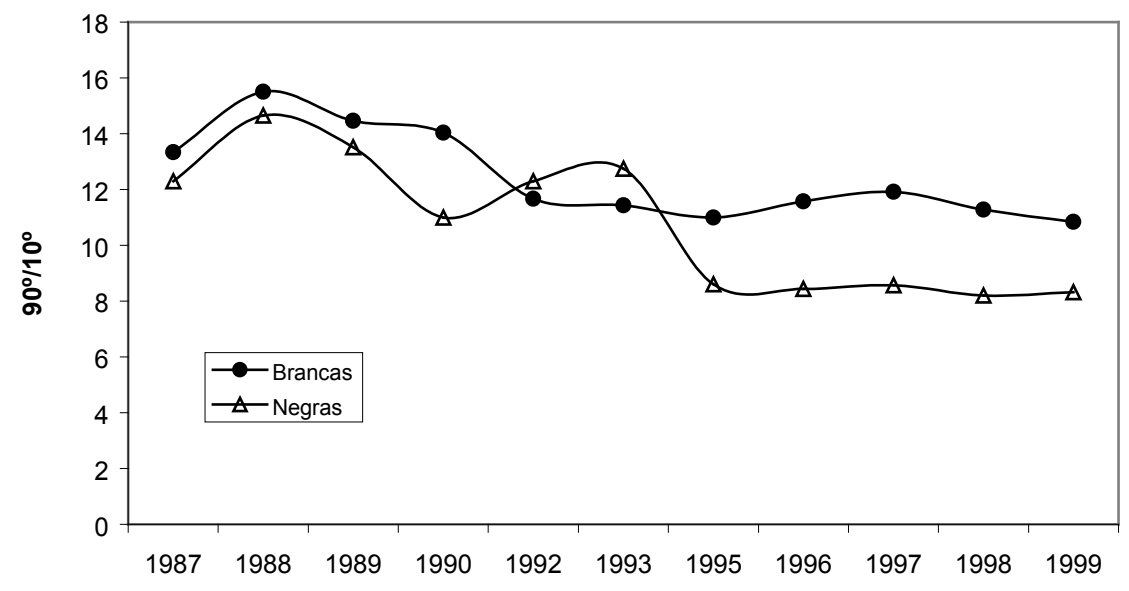

Fonte: Elaboração própria, a partir dos microdados da PNAD, IBGE, 1987-1999. 
Em 1987, esta razão era de 13,33 entre as mulheres brancas e 12,29 entre as negras. Em 1999, estes valores declinaram para 10,84 entre as mulheres brancas e 8,32 entre as negras. Portanto, houve uma redução da desigualdade entre as mulheres brancas, e em maior medida entre as negras ao longo do tempo. Isto já era de se esperar dado o maior aumento salarial das mulheres de ambas as raças nos percentis inferiores da distribuição salarial. Novamente, esta decrescente desigualdade não foi capaz de reverter as tendências da desigualdade entre as raças. Desta forma, ao contrário das tendências evidenciadas para o caso dos Estados Unidos (Blau e Beller, 1992; Juhn $e t$ al., 1991, 1993), a persistência do hiato entre as mulheres brancas e negras no Brasil ocorreu em um ambiente de decrescente desigualdade salarial dentro de cada grupo. Se a explicação para esta tendência fosse a mesma dada por Blau e Beller (1992) e Juhn et al. (1991, 1993) para os Estados Unidos, estaria associada a uma diminuição nos retornos à qualificação. Isto parece paradoxal, dado que seria de se esperar um deslocamento da demanda relativa por trabalhadores altamente qualificados, o que aumentaria os retornos de qualificação.

\subsection{Educação}

Os indicadores de mercado de trabalho são fortemente afetados por diferenças educacionais entre os trabalhadores. Os níveis de escolaridade são um determinante-chave das oportunidades salariais. Mudanças relativas das diferenças de escolaridade entre as raças são particularmente importantes quando são examinados os diferenciais salariais por raça, dado que as mulheres negras continuam a apresentar um nível de escolaridade mais baixo do que o das mulheres brancas. Estes investimentos diferenciais em educação podem estar refletindo uma discriminação pré-mercado; há evidências de que os negros recebem uma educação pública mais fraca e tendem a abandonar a escola mais cedo. Comparados às mulheres brancas, as negras tendem a ter enfrentado maiores restrições à educação, mas os diferenciais parecem estar declinando ao longo do tempo.

A Tabela 5 mostra que os níveis educacionais das mulheres negras se moveram em direção aos níveis das brancas, mas ainda permanecem relativamente baixos, e grandes disparidades raciais persistem entre todas as coortes. ${ }^{11}$ Entre os trabalhadores mais jovens, as diferenças nos anos médios de estudo entre as mulheres brancas e negras são bem menores do que entre as mulheres mais velhas. A convergência dos níveis educacionais entre as coortes levanta a hipótese de uma prospectiva convergência dos salários.

11 Os dados de coortes refletem a experiência educacional média de todos os indivíduos ao longo de todo o período estudado. 
TABELA 5 - ANOS MÉDIOS DE ESTUDO POR RAÇA E O HIATO ENTRE NEGRAS E BRANCAS, PARA COORTES DE MULHERES, BRASIL URBANO

\begin{tabular}{cccc}
\hline Coortes & Brancas & Negras & Razão Negras/Brancas \\
\hline $1973-75$ & 9,18 & 7,28 & 0,793 \\
$1970-72$ & 8,68 & 7,02 & 0,808 \\
$1967-69$ & 8,43 & 6,65 & 0,789 \\
$1964-66$ & 8,50 & 6,66 & 0,783 \\
$1961-63$ & 8,22 & 6,41 & 0,779 \\
$1958-60$ & 8,18 & 6,05 & 0,740 \\
$1955-57$ & 7,93 & 5,86 & 0,738 \\
$1952-54$ & 7,42 & 5,35 & 0,720 \\
$1949-51$ & 6,99 & 4,84 & 0,692 \\
$1946-48$ & 6,32 & 4,25 & 0,672 \\
$1943-45$ & 5,87 & 3,69 & 0,629 \\
$1940-42$ & 5,46 & 3,45 & 0,631 \\
$1937-39$ & 5,23 & 3,18 & 0,608 \\
$1934-36$ & 4,89 & 2,94 & 0,601 \\
\hline
\end{tabular}

Fonte: Elaboração própria, a partir dos microdados da PNAD, IBGE, 1987-1999.

Examinando a composição educacional da força de trabalho feminina branca e negra na Tabela 6 , a parcela da população com menos de 8 anos de estudo reduziu-se acentuadamente em ambos os grupos. Entre as mulheres brancas, aproximadamente metade da força de trabalho tinha mais de 11 anos de estudo em 1999, o que representa um enorme avanço em relação aos 35\% em 1987. Entre as mulheres negras, esta parcela também se ampliou, mas em 1999 alcançou somente cerca de um quarto da força de trabalho. Na medida em que fatores composicionais são importantes, seu impacto é uma questão empírica.

TABELA 6 - DISTRIBUIÇÃO DAS MULHERES E SALÁRIOS MÉDIOS POR RAÇA E NÍVEL EDUCACIONAL, E HIATO SALARIAL ENTRE NEGRAS E BRANCAS POR NÍVEL EDUCACIONAL, BRASIL URBANO, 1987-1999

\begin{tabular}{|c|c|c|c|c|c|c|c|c|c|c|}
\hline \multirow{3}{*}{$\begin{array}{l}\text { Anos } \\
\text { de } \\
\text { Estudo }\end{array}$} & \multicolumn{4}{|c|}{ Distribuição (\%) } & \multicolumn{4}{|c|}{ Salários Médios } & \multirow{2}{*}{\multicolumn{2}{|c|}{$\begin{array}{l}\text { Razão Salarial } \\
\text { Negras/Brancas }\end{array}$}} \\
\hline & \multicolumn{2}{|c|}{ Brancas } & \multicolumn{2}{|c|}{ Negras } & \multicolumn{2}{|c|}{ Brancas } & \multicolumn{2}{|c|}{ Negras } & & \\
\hline & 1987 & 1999 & 1987 & 1999 & 1987 & 1999 & 1987 & 1999 & 1987 & 1999 \\
\hline $0-3$ & 18,0 & 10,4 & 35,8 & 23,5 & 1,084 & 1,401 & 0,836 & 0,970 & 0,771 & 0,692 \\
\hline $4-7$ & 31,2 & 25,1 & 34,4 & 32,0 & 1,434 & 1,563 & 1,098 & 1,170 & 0,766 & 0,748 \\
\hline 8-10 & 15,4 & 17,7 & 13,2 & 17,1 & 2,212 & 1,973 & 1,684 & 1,460 & 0,761 & 0,740 \\
\hline $11-14$ & 24,1 & 31,7 & 13,8 & 22,9 & 3,999 & 3,483 & 3,111 & 2,371 & 0,778 & 0,681 \\
\hline $15-+$ & 11,3 & 15,2 & 2,8 & 4,6 & 8,672 & 9,121 & 8,187 & 6,887 & 0,944 & 0,755 \\
\hline
\end{tabular}

Fonte: Elaboração própria, a partir dos microdados da PNAD, IBGE, 1987-1999. 
A Tabela 6 também mostra que as mulheres menos escolarizadas (0-7 anos de estudo) tiveram maiores ganhos do que as mulheres mais escolarizadas (exceto as mulheres brancas no grupo superior) em termos de crescimento acumulado do salário real entre 1987 e 1999. Em todos os grupos educacionais, as tendências para as mulheres brancas foram mais favoráveis do que para o grupo de mulheres negras correspondentes. As razões salariais entre as mulheres negras e brancas específicas por grupo educacional também são exibidas na Tabela 6. Estes dados mostram que as mulheres negras de todos os grupos educacionais, em adição a todos os grupos etários, não conseguiram reduzir o hiato relativo a seus pares brancos, mas as perdas relativas foram muito diferentes em magnitude para os grupos: o aumento do hiato foi maior entre as mais escolarizadas.

\subsection{Tendências de Outros Determinantes dos Diferenciais Salariais}

(a) Background Familiar: a incidência de famílias chefiadas por mulheres solteiras com filhos entre as mulheres negras estava acima de $20 \%$ em 1987 e aumentou 3,3 pontos porcentuais em 1999. Este aumento foi similar ao das mulheres brancas ( 3,8 pontos porcentuais), mas estas se situavam em $14 \%$ em 1987. Estes aumentos significam que cresce o segmento da população feminina cujo bem-estar econômico depende dos seus níveis salariais. Em 1987 e 1999, os salários das mulheres negras nestas famílias chefiadas por mulheres são os mais baixos, e correspondem a cerca de metade dos salários das mulheres brancas neste tipo de família. Principalmente entre as mulheres negras isto é muito preocupante, tendo em vista que, comparadas às brancas, elas tendem mais a pertencer a famílias com recursos limitados. Em $1999,6 \%$ das mulheres brancas e $16 \%$ das negras estavam no décimo inferior da distribuição de renda familiar. No décimo superior desta distribuição, a fração de mulheres brancas era $15 \%$, enquanto a de negras era somente $3 \%$.

(b) Região: a proporção de mulheres negras no Nordeste é aproximadamente o dobro das outras regiões. Na medida em que os mercados de trabalho locais diferem, e a força de trabalho é pouco móvel no curto prazo, diferenças na localização regional são determinantes dos resultados do mercado de trabalho. Quanto aos salários médios por região, há uma clara hierarquia entre as regiões. Os salários das mulheres brancas são sempre mais elevados no Sudeste, o que se observa para as negras em 1999. O hiato salarial entre negras e brancas é menor no Nordeste; em ambas as regiões este hiato tendeu a declinar ao longo do tempo.

(c) Demanda de Qualificação das Ocupações: com o propósito de investigar diferenças por raça na estrutura ocupacional, o espectro ocupacional foi dividido em grupos, de acordo com a demanda por qualificação de cada ocupação: alta, média, 
baixa e trabalho doméstico. ${ }^{12}$ Esta última categoria foi separada do nível baixo devido à sua magnitude e baixos salários, sobretudo entre as mulheres negras. As diferenças ocupacionais por raça são grandes: as mulheres negras estão muito mais concentradas nas ocupações menos qualificadas, que remuneram pior, mas onde o hiato salarial por raça é menor em 1999. Para as mulheres brancas e negras, os salários médios por categoria ocupacional revelam uma clara hierarquia, que tende a suavizar ao longo do tempo. Enquanto em 1987 o hiato era mais baixo nas ocupações mais qualificadas, o oposto foi observado em 1999.

(d) Grau de Feminização das Ocupações: visando a explorar mais as diferenças por raça na estrutura ocupacional, o espectro das ocupações foi redividido de acordo com o grau de feminização de cada uma: femininas, integradas e masculinas. ${ }^{13} \mathrm{~A}$ razão para considerar diferenças de gênero nas distribuições ocupacionais é a sua associação com os níveis salariais. A proporção de mulheres em uma ocupação é negativamente associada com seus salários. (Oliveira, 2001). Portanto, se as mulheres negras estão mais concentradas em ocupações femininas, elas provavelmente serão mais prejudicadas. As diferenças ocupacionais por raça segundo esta tipologia são significativas e tenderam a aumentar ao longo do tempo: as mulheres negras se inserem mais em ocupações femininas, nas quais os salários são mais baixos, mas onde o hiato é menor e apresenta uma tendência descendente ao longo do tempo. O hiato salarial entre as mulheres negras e brancas é maior nas ocupações integradas e masculinas, nas quais apresenta uma tendência ascendente. Novamente os salários médios por categoria revelam uma hierarquia, que diminuiu pouco entre 1987 e 1999.

(e) Setor de Atividade: para examinar diferenças por raça na estrutura setorial, uma classificação foi construída tentando captar a heterogeneidade no setor industrial moderno e tradicional ${ }^{14}$ - e no setor de serviços - distributivos, produtivos, sociais

12 A demanda por qualificação das ocupaçôes se relaciona ao nível de instrução média necessária ao seu desempenho combinado às diferentes formas de inserção na produção. Por exemplo, empregadores, trabalhadores em ocupaçôes técnicas, científicas e profissionais, juntamente com gerentes e supervisores, compõem a categoria "alta".

13 Esta tipologia usa as porcentagens de mulheres e homens em uma ocupação como base para a classificação. Propõe-se um intervalo central em torno da proporção feminina média na força de trabalho, definindo o que constitui uma ocupação integrada, predominantemente feminina ou masculina. As ocupações integradas são definidas como aquelas localizadas em um intervalo em torno da razão de sexo da força de trabalho como um todo, no caso, no intervalo de 20 pontos porcentuais em torno da participação feminina na força de trabalho para cada ano ao longo do período estudado. As ocupaçóes em cada lado da categoria média são predominantemente femininas ou masculinas; as femininas são aquelas que têm uma proporção de mulheres acima do limite superior do intervalo definido em torno da média e as masculinas são aquelas que têm uma proporção de mulheres abaixo do limite inferior do intervalo.

14 Incluem-se no setor industrial moderno as indústrias metalúrgicas, mecânicas, de material elétrico e eletrônico, de papel e papelão, de borracha, químicas, de produção de petróleo, farmacêuticas e de produtos plásticos. No setor industrial tradicional, estão incluídas as indústrias de transformação de 
e pessoais. ${ }^{15}$ As mulheres brancas e negras tendem a estar concentradas nos serviços, especialmente pessoais, onde os salários são mais baixos e o hiato é menor. As mulheres brancas estão mais uniformemente distribuídas entre os setores.

(f) Setor Informal: a segmentação do mercado de trabalho urbano no Brasil pode ser indicada pela divisão entre um setor formal, constituído por empregados com carteira assinada e empregadores, e um informal, composto por empregados sem carteira assinada e trabalhadores por conta própria. Comparadas às mulheres brancas, as negras estão mais concentradas no setor informal: cerca de $60 \%$ delas estão ocupadas neste setor. Aumentos na proporção informal prevaleceram em ambos os grupos raciais, e isto também é preocupante, dado que os salários neste setor são extremamente baixos quando comparados ao setor formal e o hiato salarial entre as raças é maior.

(g) Trabalho em Tempo Parcial: com o propósito de considerar a questão da flexibilidade do trabalho em termos da sua jornada, as mulheres negras e brancas foram divididas entre trabalhadoras em tempo parcial - 30 horas ou menos por semana - e em tempo integral - mais de 30 horas por semana. As mulheres de ambas as raças estão concentradas no trabalho em tempo integral, e isto parece estar diminuindo entre as mulheres negras. Considerando que os salários das trabalhadoras em tempo integral são mais baixos do que os daquelas em tempo parcial, isto poderia ser benéfico para as negras. $\mathrm{O}$ hiato salarial por raça é similar entre os grupos de horas trabalhadas.

A descrição destes aspectos da inserção diferencial das mulheres no mercado de trabalho visa a subsidiar as hipóteses sobre a direção e a magnitude dos determinantes dos diferenciais salariais por raça, a serem incluídos na análise multivariada. Assim, os diferenciais salariais controlados pela idade, pelo período, pela coorte, pelo nível de escolaridade, pela região, pelo background familiar e pela inserção ocupacional entre as mulheres brancas e negras parecem ser extremamente relevantes.

\section{METODOLOGIAS PARA DECOMPOR O HIATO SALARIAL POR RAÇA}

Uma maneira de explorar o hiato dos salários por raça é por meio de uma série de modelos simples de determinação salarial. Assume-se que os salários para uma mulher i podem ser escritos como:

materiais não metálicos, de madeira, de artigos de papel, de mobiliário, têxteis, do vestuário, de calçados, de produtos alimentícios, de bebidas, de fumo e editoriais e gráficas.

15 Compõem a categoria dos serviços distributivos, os serviços de comércio, transporte e comunicação; os serviços produtivos são constituídos pelos serviços técnico-profissionais, serviços de diversões, radiofusão e televisão, serviços industriais de utilidade pública e serviços auxiliares das atividades econômicas; os serviços sociais incluem os serviços comunitários, os serviços médicos e de ensino; e os serviços pessoais agregam os serviços de alojamento e alimentação, reparação e conservação e domiciliares. 
$\log \left(\mathrm{W}_{\mathrm{i}}\right)=\beta_{1} \mathrm{X}_{\mathrm{i}}+\beta_{2 \mathrm{t}} \mathrm{R}_{\mathrm{i}}+v_{\mathrm{i}}$

onde $\mathrm{W}$ representa o salário de uma mulher, $\mathrm{X}$ é um conjunto de variáveis de controle individuais tais como características pessoais e ocupacionais, e $\mathrm{R}$ é uma variável dummy para raça $(1=$ negras vs. $0=$ brancas). Esta expressão configura uma relação log-linear entre o logaritmo do salário e os atributos produtivos $\mathrm{X}$, tais como idade $\mathrm{e}$ educação, que exercem uma forte influência sobre a produtividade dos trabalhadores. Este vetor de características também inclui informações sobre os atributos da inserção ocupacional do trabalhador, tais como setor de atividade, região de residência e trabalho formal. Nesta equação, os coeficientes $\beta$ são interpretados como o preço implícito de cada atributo que aumenta a produtividade do trabalhador. Se não há discriminação racial no mercado de trabalho, os preços implícitos destes atributos seriam os mesmos para todas as mulheres. Caso contrário, alguns atributos seriam menos recompensados se as mulheres não fossem brancas, por exemplo. Isto significa que a discriminação pode assumir diferentes formas, prejudicando um ou mais atributos produtivos, só porque as mulheres negras os possuem. A inclusão de uma variável dummy para a raça pretende avaliar a discriminação média, dado que o montante de cada atributo é controlado na estimação dos coeficientes. Portanto, $\mathrm{R}$ indica a identidade de raça e seu coeficiente indica a discriminação enfrentada pelo grupo racial.

Ao usar dados longitudinais para estimar os efeitos de idade, período e coorte nas equações de rendimentos individuais pressupõe-se que a função de rendimentos do indivíduo i depende da idade $\mathrm{a}_{\mathrm{i}}$, ano $\mathrm{t}$, coorte $\mathrm{c}_{\mathrm{i}}$ e nível de escolaridade $\mathrm{e}_{\mathrm{i}}$ (omitindo as outras covariáveis para facilitar a exposição). Vamos adotar uma função linear:

$$
\mathrm{W}_{\mathrm{i}}\left(\mathrm{t}, \mathrm{a}_{\mathrm{i}}, \mathrm{c}_{\mathrm{i}}, \mathrm{e}_{\mathrm{i}}\right)=\beta_{0}+\beta_{1} \mathrm{a}_{\mathrm{i}}+\beta_{2} \mathrm{t}+\beta_{3} \mathrm{e}_{\mathrm{i}}+\beta_{4} \mathrm{c}_{\mathrm{i}}
$$

onde $\mathrm{W}$ é uma transformação monotônica dos rendimentos. Todas as variáveis nesta equação podem ser consideradas como proxies para variáveis subjacentes não observadas, as quais não são linearmente dependentes. Como mencionado anteriormente, a idade $\left(a_{i}\right)$ pode ser um determinante direto dos rendimentos por meio da experiência de trabalho e treinamento. Os efeitos de período (t) são proxies para variáveis macroeconômicas ou variáveis gerais do mercado de trabalho que afetam a força de trabalho como um todo e determinam os rendimentos individuais. A escolaridade $\left(\mathrm{e}_{\mathrm{i}}\right)$ é uma proxy para habilidade e produtividade, atuando positivamente sobre os rendimentos. $\mathrm{E}$ a variável de coorte $\left(\mathrm{c}_{\mathrm{i}}\right)$ representa vários fenômenos específicos de coorte, refletindo mudanças permanentes na composição da população. Estes argumentos justificam a lista de variáveis incluídas na equação, mas não necessariamente a forma funcional da equação. Não é possível estimar todos os coeficientes da equação sem restrições adicionais devido às interdependências conceituais entre as variáveis: $t=a_{i}+c_{i}$. A estimação direta da equação por mínimos quadrados é impossível devido à multico- 
linearidade entre as variáveis. A maneira pela qual são definidas as variáveis de idade, período e coorte obedece a relações lineares exatas entre elas. Isto significa que não é possível afirmar que as variáveis do lado direito variem independentemente; assim, a equação não é identificada. O problema de identificação implica que a questão central a ser considerada é se dados longitudinais podem ser usados para identificar parâmetros adicionais na equação 2 e que podem ser identificados a partir de pesquisas crosssection. Esta discussão sobre identificação se aplica tanto se as variáveis são medidas como contínuas quanto como categóricas, e não há solução sem restrições adicionais. Modelos com interações de ordem mais alta também têm problemas de dependências lineares, e nem todos os coeficientes podem ser estimados.

Para implementar este modelo foi preciso decidir como rotular as coortes. Neste artigo, para os efeitos de período, já que não há um padrão óbvio a priori, variáveis dummy foram utilizadas, mas efeitos de idade puderam razoavelmente ser modelados como polinômios da idade. Tendo em vista que os dados são abundantes, não houve razão para não usar variáveis dummy para representar os efeitos de coorte, permitindo aos dados escolher qualquer padrão. O objetivo é detectar qualquer indicação de reversão futura da tendência observada de persistência dos diferenciais salariais por raça entre as mulheres. Se verificarmos uma variação positiva entre as coortes, então poderemos esperar um real progresso em direção a uma maior igualdade racial. A estimação dos efeitos separados de idade, período, coorte, escolaridade e outras covariáveis na equação de rendimentos individuais requer, então, a utilização de estratégias para lidar com o problema de identificação. No caso, foram restritos os coeficientes das coortes mais velhas a serem iguais.

Feitas estas colocações, são então adotados procedimentos padrões de estimação de regressões com e sem controles para características pessoais e ocupacionais. A escolha das características produtivas a serem incluídas nas equações salariais é fundamental. O panorama descrito acima acerca das diferenças no mercado de trabalho entre as mulheres brancas e negras subsidiou esta escolha. As regressões que não controlam por estas variáveis subestimam a importância destas características sobre os resultados de mercado de trabalho. Por outro lado, as regressóes que controlam inteiramente por estas variáveis subestimam os efeitos das restrições do mercado de trabalho. Diferenças nas características ocupacionais entre os empregos das mulheres brancas e negras - tais como setor de atividade, trabalho em tempo parcial etc. - podem ser consideradas como restrições que as mulheres negras encontram no mercado de trabalho. Foi mostrado acima que há diferenças relevantes na distribuição ocupacional das mulheres segundo a raça; tais diferenças implicam grandes diferenciais nas características das ocupações das mulheres brancas e negras. Estes diferenciais podem explicar uma parte do hiato salarial entre elas. Neste sentido, o efeito da localização ocupacional sobre o hiato por raça é uma questão-chave. 
Em seguida, é feita uma abordagem padrão para explorar o hiato salarial entre os grupos raciais, decompondo-o em componentes "explicados" e "não explicados". Assumese que o salário para uma mulher branca (grupo l) pode ser escrito como

$$
\log \left(\mathrm{W}_{1 \mathrm{i}}\right)=\beta_{1} \mathrm{X}_{1 \mathrm{i}}+U_{1 \mathrm{i}}
$$

e o salário para uma mulher negra pode ser escrito como:

$$
\log \left(\mathrm{W}_{2 \mathrm{j}}\right)=\beta_{2} \mathrm{X}_{2 \mathrm{j}}+\mathrm{U}_{2 \mathrm{j}}
$$

onde $\beta_{1}$ e $\beta_{2}$ são definidos tal que $\mathrm{E}\left(v_{1 \mathrm{i}} \mid \mathrm{X}_{1 \mathrm{i}}\right)=0$ and $\mathrm{E}\left(v_{2 \mathrm{j}} \mid \mathrm{X}_{2 \mathrm{j}}\right)=0$. A diferença entre os salários médios pode ser escrita como:

$$
\mathrm{W}_{1}-\mathrm{W}_{2}=\left(\mathrm{X}_{1}-\mathrm{X}_{2}\right) \beta_{1}+\left(\beta_{1}-\beta_{2}\right) \mathrm{X}_{2}
$$

onde $\mathrm{W}_{\mathrm{g}}$ e $\mathrm{X}_{\mathrm{g}}$ representam os salários médios e as características de controle para todos os indivíduos no grupo g. O primeiro termo desta decomposição representa o componente explicado, devido a diferenças médias nas características produtivas das mulheres brancas e negras. Ele indica o hiato racial previsto usando o grupo 1 - mulheres brancas - como referência. ${ }^{16} \mathrm{O}$ segundo termo é o componente não explicado e representa diferenças nos coeficientes estimados, ou seja, diferenças nos retornos a características similares entre as mulheres brancas e negras. A parte do hiato salarial total devida a este componente capta os efeitos da discriminação e das diferenças não observadas entre os grupos. ${ }^{17}$

Altonji e Blank (1998) apontam que uma desvantagem desta decomposição é que ela não fornece muita indicação sobre como o hiato salarial é afetado pela distribuição salarial geral (o que ocorre quando os retornos à qualificação são diferentes). Aumentos na dispersão dos salários aumentariam o hiato entre os salários médios das mulheres brancas e negras, mesmo que estas mudanças não tenham efeito sobre a localização das distribuições dos dois grupos. Para analisar o efeito da distribuição dos salários sobre o hiato salarial entre as mulheres brancas e negras, a técnica de decomposição acima foi aplicada a diferentes percentis da distribuição salarial das mulheres. Estimativas dos coeficientes foram obtidas a partir de regressões quantílicas para o $10^{\circ}, 50^{\circ}$ (mediana) e $90^{\circ}$ percentis das distribuiçôes salariais das mulheres brancas e negras.

16 Vale ressaltar que este componente pode ser afetado por barreiras discriminatórias no mercado de trabalho ou fora dele, que afetam os Xs, as características dos indivíduos no mercado de trabalho.

17 Dado que variáveis de controle potencialmente importantes são omitidas e correlacionadas com os Xs incluídos, afetando os coeficientes $\beta$. 
A regressão quantílica, assim como a regressão linear, se refere à distribuição dos salários condicional ao vetor de covariáveis. Na regressão linear, assume-se que uma característica desta distribuição, a média, é uma função linear das covariáveis. A regressão quantílica é útil quando, ao invés da média, se quer trabalhar com a mediana, e assumir que as medianas dos salários condicionais às covariáveis são lineares nestas covariáveis, ou ajustar uma função linear às medianas (regressão mediana ou regressão quantílica em 0.5). Em princípio, é possível fazer o mesmo para qualquer outro quantil da distribuição. Verificando diferentes regressões quantílicas é possível explorar diferentes partes da distribuição condicional. Na relação entre salários e escolaridade, por exemplo, a um dado nível de escolaridade, há uma distribuição (condicional) de salários, presumivelmente refletindo habilidade e outras qualificações para o mercado de trabalho não observadas. Em geral, não há razão para exigir que a taxa de retorno a um ano adicional de escolaridade seja o mesmo em todos os pontos da distribuição de qualificação condicional na escolaridade, e a regressão quantílica capta estas diferenças. Usada desta maneira, a regressão quantílica é uma técnica semiparamétrica que descreve a forma da distribuição empírica sem impor restrições anteriores, mas impondo uma forma funcional linear para os parâmetros do modelo. Se a distribuição condicional muda a forma com uma ou mais variáveis explicativas, as regressões quantílicas nos diferentes quantis têm diferentes inclinações. (Deaton, 1995). A estimação das regressões quantílicas baseia-se em extensões do resultado de que a mediana é o ponto mais próximo aos dados no sentido de minimizar a soma dos desvios absolutos. Os parâmetros da regressão linear mediana são dados como o valor do vetor $\beta$ que minimiza ${ }^{18}$

$$
\sum_{i=1}^{n}\left|y_{i}-x_{i}^{\prime} \beta\right|=\sum_{i=1}^{n}\left(0.5-1\left(y_{i} \geq x_{i}^{\prime} \beta\right)\right)\left(y_{i}-x_{i}^{\prime} \beta\right)
$$

\section{ESTIMANDO MODELOS DE DETERMINAÇÃO SALARIAL}

Nesta seção, os hiatos salariais por raça entre as mulheres são explorados por meio de uma série de modelos de determinação salarial, buscando estimar como os diferenciais dos salários se relacionam a diferenças em características e diferenças no tratamento do mercado de trabalho, dadas as características. Como mencionado acima, as regressóes salariais foram estimadas usando os dados a partir das pesquisas cross sections repetidas. As características pessoais incluídas foram: anos de estudo, idade e idade ao quadrado, dummies para chefia do domicílio (chefe $=1$ ), presença de filhos menores de 6 anos

18 O estimador dos outros quantis pode ser calculado por meio da minimização de uma generalização desta expressão: $\tilde{\beta}=\arg \min \sum_{i=1}^{n}\left(p-1\left(y_{i} \geq x_{i}^{\prime} \beta\right)\right)\left(y_{i}-x_{i}^{\prime} \beta\right)$. Apesar destas expressões não permitirem soluçóes explícitas, os parâmetros podem ser obtidos mediante métodos de programação linear. 
$(\operatorname{sim}=1)$, regiões (Sudeste, Nordeste e outras) e residência em uma área metropolitana $(\operatorname{sim}=1)$. As variáveis ocupacionais são dummies para jornada de trabalho (tempo integral $=1$ ), segmento (informal=1), setores de atividade (9), categorias da tipologia de integração das ocupações (masculinas, integradas, feminina) e categorias do nível de qualificação das ocupações (alto, médio, baixo, trabalho doméstico). Além disto, dummies para anos e coortes foram incluídas para controlar seus efeitos nos dados acumulados das cross sections. A Tabela 7 mostra as diferenças nos coeficientes de raça entre as especificações das regressões com e sem controles. A primeira especificação é uma regressão do logaritmo dos salários/hora sobre a variável dummy de raça (negras=1), controlando somente pelos períodos. A segunda especificação inclui controles por características pessoais. A terceira inclui controles adicionais pelas características ocupacionais. E a quarta especificação controla pelos efeitos das coortes.

À medida que as características de controle são adicionadas ao modelo, o efeito negativo da raça sobre os salários torna-se menos significativo. A inclusão das características pessoais à regressão reduz muito a parcela não explicada do diferencial, ou seja, os efeitos negativos da raça são substancialmente menores, sugerindo que estas características são muito diferentes entre as mulheres. Adicionando as variáveis ocupacionais à regressão, diminui um pouco mais o efeito da variável de raça sobre os salários. As mulheres negras recebem salários/hora $34 \%$ mais baixos do que as brancas se nenhuma variável de controle é incluída, 19\% menos controlando por características pessoais e $14 \%$ menos quando o conjunto completo de variáveis de controle é incluído. Acrescentar o controle pelos efeitos de coorte não altera o efeito da variável de raça. Como esperado, a partir das evidências descritivas, os diferenciais entre as coortes não são estatisticamente significantes, controlando pelas outras variáveis. Os resultados da Tabela 7 mostram que há diferenças significativas e persistentes no mercado de trabalho feminino, mesmo controlando pelas características ocupacionais. Os efeitos negativos remanescentes enfrentados pelas mulheres negras indicam que há restriçóes não explicadas aos seus retornos do mercado de trabalho.

Com o propósito de decompor o diferencial, considerando a heterogeneidade das mulheres segundo a raça, é feita a análise de se os retornos às características são os mesmos para as brancas e negras, estimando equações de mínimos quadrados para cada raça separadamente. ${ }^{19}$ Se os retornos são equivalentes, então a mudança na penalidade por ser negra se deve à aquisição de diferentes níveis de características entre as raças. A Tabela 8 usa o procedimento de decomposição mostrado na equação 4 para decompor o hiato do logaritmo dos salários/hora entre as mulheres brancas e negras.

19 Os coeficientes destas regressões estão no anexo. 
TABELA 7 - COEFICIENTES DAS REGRESSÕES SALARIAIS POR RAÇA

\begin{tabular}{|c|c|c|c|c|c|c|c|c|c|c|c|c|}
\hline & \multicolumn{3}{|c|}{ Modelo 1} & \multicolumn{2}{|c|}{ Modelo 2} & & \multicolumn{3}{|c|}{ Modelo 3} & \multicolumn{3}{|c|}{ Modelo 4} \\
\hline Raça & $-0,571$ & $(0,005)$ & * & $-0,171$ & $(0,004)$ & * & $-0,134$ & $(0,004)$ & * & $-0,134$ & $(0,004)$ & * \\
\hline 1996 & 0,061 & $(0,008)$ & * & 0,105 & $(0,006)$ & * & 0,083 & $(0,006)$ & * & 0,072 & $(0,008)$ & * \\
\hline 1993 & $-0,228$ & $(0,008)$ & * & $-0,125$ & $(0,006)$ & * & $-0,171$ & $(0,006)$ & * & $-0,191$ & $(0,014)$ & * \\
\hline 1990 & $-0,063$ & $(0,008)$ & * & 0,051 & $(0,006)$ & * & $-0,033$ & $(0,006)$ & * & $-0,059$ & $(0,020)$ & * \\
\hline 1987 & $-0,052$ & $(0,009)$ & * & 0,125 & $(0,007)$ & * & 0,044 & $(0,006)$ & * & 0,013 & $(0,026)$ & \\
\hline Idade & & & & 0,054 & $(0,002)$ & * & 0,051 & $(0,002)$ & * & 0,034 & $(0,003)$ & * \\
\hline Idade $^{2}$ & & & & $-0,001$ & $(0,000)$ & * & $-0,001$ & $(0,000)$ & * & 0,000 & $(0,000)$ & * \\
\hline Estado Conjugal & & & & 0,232 & $(0,006)$ & * & 0,205 & $(0,006)$ & * & 0,205 & $(0,006)$ & * \\
\hline Filhos menos & & & & $-0,007$ & $(0,005)$ & & $-0,017$ & $(0,005)$ & * & $-0,016$ & $(0,005)$ & * \\
\hline $\begin{array}{l}6 \text { anos } \\
\text { Chefe do Domicílio }\end{array}$ & & & & 0,172 & $(0,007)$ & * & 0,183 & $(0,006)$ & * & 0,183 & $(0,006)$ & * \\
\hline Anos de Estudo & & & & 0,139 & $(0,001)$ & * & 0,089 & $(0,001)$ & * & 0,088 & $(0,001)$ & * \\
\hline Área Metropolitana & & & & 0,164 & $(0,004)$ & * & 0,187 & $(0,004)$ & * & 0,187 & $(0,004)$ & * \\
\hline Sudeste & & & & $-0,006$ & $(0,005)$ & & 0,003 & $(0,004)$ & & 0,003 & $(0,004)$ & \\
\hline Nordeste & & & & $-0,324$ & $(0,005)$ & * & $-0,365$ & $(0,005)$ & * & $-0,365$ & $(0,005)$ & * \\
\hline Indústria Moderna & & & & & & & 0,296 & $(0,017)$ & * & 0,296 & $(0,017)$ & * \\
\hline Indústria Tradicional & & & & & & & 0,117 & $(0,013)$ & * & 0,117 & $(0,013)$ & * \\
\hline Serv. Distributivos & & & & & & & 0,207 & $(0,012)$ & * & 0,207 & $(0,012)$ & * \\
\hline Serv. Produtivos & & & & & & & 0,332 & $(0,013)$ & * & 0,332 & $(0,013)$ & * \\
\hline Serv. Pessoais & & & & & & & 0,074 & $(0,012)$ & * & 0,075 & $(0,012)$ & * \\
\hline Serv. Sociais & & & & & & & 0,098 & $(0,012)$ & * & 0,099 & $(0,012)$ & * \\
\hline Administr. Pública & & & & & & & 0,277 & $(0,014)$ & * & 0,277 & $(0,014)$ & * \\
\hline Ocup. Alto Nível & & & & & & & 0,657 & $(0,008)$ & * & 0,657 & $(0,008)$ & * \\
\hline Ocup. Médio Nível & & & & & & & 0,295 & $(0,007)$ & * & 0,295 & $(0,007)$ & * \\
\hline Trabalho Doméstico & & & & & & & $-0,080$ & $(0,007)$ & * & $-0,081$ & $(0,007)$ & * \\
\hline Tempo Integral & & & & & & & $-0,376$ & $(0,004)$ & * & $-0,376$ & $(0,004)$ & * \\
\hline Setor Informal & & & & & & & $-0,132$ & $(0,005)$ & * & $-0,131$ & $(0,005)$ & * \\
\hline Ocupação Feminina & & & & & & & $-0,219$ & $(0,007)$ & * & $-0,219$ & $(0,007)$ & * \\
\hline $\begin{array}{l}\text { Ocupação } \\
\text { Integrada }\end{array}$ & & & & & & & $-0,036$ & $(0,008)$ & * & $-0,036$ & $(0,008)$ & * \\
\hline Coorte 1973-75 & & & & & & & & & & $-0,045$ & $(0,093)$ & \\
\hline Coorte 1970-72 & & & & & & & & & & $-0,022$ & $(0,086)$ & \\
\hline Coorte 1967-69 & & & & & & & & & & 0,003 & $(0,080)$ & \\
\hline Coorte 1964-66 & & & & & & & & & & 0,011 & $(0,074)$ & \\
\hline Coorte 1961-63 & & & & & & & & & & 0,019 & $(0,068)$ & \\
\hline Coorte $1958-60$ & & & & & & & & & & 0,040 & $(0,062)$ & \\
\hline Coorte 1955-57 & & & & & & & & & & 0,058 & $(0,056)$ & \\
\hline Coorte 1952-54 & & & & & & & & & & 0,081 & $(0,051)$ & \\
\hline Coorte 1949-51 & & & & & & & & & & 0,075 & $(0,045)$ & *** \\
\hline Coorte 1946-48 & & & & & & & & & & 0,089 & $(0,039)$ & ** \\
\hline Coorte 1943-45 & & & & & & & & & & 0,063 & $(0,034)$ & *** \\
\hline Coorte 1940-42 & & & & & & & & & & 0,053 & $(0,029)$ & *** \\
\hline Coorte $1937-39$ & & & & & & & & & & 0,034 & $(0,024)$ & \\
\hline Coorte 1934-36 & & & & & & & & & & 0,034 & $(0,021)$ & \\
\hline
\end{tabular}

Fonte: Elaboração própria, a partir dos microdados da PNAD, IBGE, 1987-1999.

Nota: ${ }^{* *}$ significante a $0,10,{ }^{*}$ significante a $0,05,{ }^{*}$ significante a 0,01 . 
A Tabela 8 mostra o hiato total dos salários/hora entre os grupos raciais, e a decomposição deste hiato em uma parcela devida a diferenças nas características - parte explicada - e diferenças nos coeficientes - parte não explicada - para as especificações dos modelos acima. Movendo da especificação parcial do modelo 2 para a especificação completa do modelo 3 , a parcela do hiato salarial explicada pelas características aumenta. Isto já era esperado, dado que as características ocupacionais estão mais completamente controladas. Fica claro que os diferenciais educacionais continuam a afetar negativamente os salários das mulheres negras. Adicionalmente, os retornos de educação para as mulheres brancas são maiores do que para as negras. Diferentes retornos de idade também são responsáveis por uma grande parte das diferenças não explicadas, o que aumenta à medida que são incluídas mais variáveis, inclusive as variáveis de coorte no modelo 4 . Uma grande fração dos efeitos dos coeficientes se deve a um termo de intercepto mais elevado para as mulheres negras, o que compensa parcialmente os efeitos do hiato não explicado.

TABELA 8 - DECOMPOSIÇÃO DO HIATO SALARIAL POR RAÇA

\begin{tabular}{|c|c|c|c|c|c|c|c|c|c|}
\hline & \multicolumn{3}{|c|}{ Modelo 2} & \multicolumn{3}{|c|}{ Modelo 3} & \multicolumn{3}{|c|}{ Modelo 4} \\
\hline & Explic. & Não Exp. & Total & Explic. & Não Exp. & Total & Explic. & Não Exp. & Total \\
\hline Intercepto & & $-0,186$ & $-0,186$ & & $-0,178$ & $-0,178$ & & $-0,234$ & $-0,234$ \\
\hline 1996 & 0,001 & $-0,001$ & 0,000 & 0,000 & 0,000 & 0,000 & 0,000 & 0,000 & 0,000 \\
\hline 1993 & 0,000 & 0,000 & 0,000 & 0,000 & 0,001 & 0,001 & 0,000 & 0,001 & 0,002 \\
\hline 1990 & $-0,001$ & 0,009 & 0,008 & 0,000 & 0,011 & 0,011 & 0,000 & 0,011 & 0,012 \\
\hline 1987 & 0,001 & 0,002 & 0,003 & 0,000 & 0,005 & 0,005 & 0,000 & 0,005 & 0,005 \\
\hline Idade & $-0,008$ & 0,123 & 0,115 & $-0,008$ & 0,242 & 0,234 & $-0,006$ & 0,389 & 0,384 \\
\hline Idade $^{2}$ & 0,007 & $-0,022$ & $-0,015$ & 0,007 & $-0,066$ & $-0,059$ & 0,005 & $-0,141$ & $-0,136$ \\
\hline Estado Conjugal & 0,012 & 0,009 & 0,021 & 0,011 & 0,011 & 0,022 & 0,011 & 0,011 & 0,022 \\
\hline Filhos - 6 anos & 0,000 & 0,011 & 0,011 & 0,000 & 0,009 & 0,009 & 0,000 & 0,009 & 0,009 \\
\hline Chefe Domicílio & $-0,012$ & 0,008 & $-0,004$ & $-0,013$ & 0,005 & $-0,008$ & $-0,013$ & 0,005 & $-0,007$ \\
\hline Anos de Estudo & 0,363 & 0,118 & 0,481 & 0,234 & 0,086 & 0,320 & 0,234 & 0,085 & 0,319 \\
\hline Área Metropolit. & 0,001 & 0,025 & 0,026 & 0,001 & 0,010 & 0,011 & 0,001 & 0,010 & 0,011 \\
\hline Sudeste & 0,004 & 0,039 & 0,043 & 0,003 & 0,025 & 0,028 & 0,003 & 0,025 & 0,029 \\
\hline Nordeste & 0,070 & 0,017 & 0,087 & 0,079 & 0,015 & 0,094 & 0,079 & 0,015 & 0,094 \\
\hline Ind. Moderna & & & & 0,003 & $-0,002$ & 0,001 & 0,003 & $-0,002$ & 0,002 \\
\hline Ind. Tradicional & & & & 0,001 & $-0,001$ & 0,000 & 0,001 & $-0,001$ & 0,000 \\
\hline Serv. Distributivos & & & & 0,003 & $-0,016$ & $-0,013$ & 0,004 & 0,001 & 0,005 \\
\hline Serv. Produtivos & & & & 0,014 & $-0,001$ & 0,013 & 0,007 & $-0,006$ & 0,001 \\
\hline Serv. Pessoais & & & & 0,003 & $-0,006$ & $-0,003$ & 0,016 & $-0,003$ & 0,012 \\
\hline Serv. Sociais & & & & $-0,010$ & $-0,018$ & $-0,028$ & $-0,008$ & $-0,012$ & $-0,020$ \\
\hline Administr. Pública & & & & 0,003 & 0,001 & 0,004 & 0,001 & $-0,002$ & $-0,002$ \\
\hline Ocup. Alto Nível & & & & 0,071 & $-0,004$ & 0,067 & 0,031 & 0,002 & 0,033 \\
\hline Ocup. Médio Nível & & & & 0,025 & 0,003 & 0,028 & 0,053 & $-0,012$ & 0,040 \\
\hline Trab. Doméstico & & & & 0,009 & 0,000 & 0,009 & $-0,030$ & 0,003 & $-0,027$ \\
\hline Tempo Integral & & & & $-0,005$ & 0,033 & 0,028 & $-0,001$ & $-0,002$ & $-0,003$ \\
\hline Setor Informal & & & & 0,012 & 0,048 & 0,060 & 0,043 & 0,026 & 0,069 \\
\hline Ocup. Feminina & & & & 0,019 & $-0,078$ & $-0,059$ & 0,007 & 0,070 & 0,077 \\
\hline Ocup. Integrada & & & & $-0,001$ & $-0,006$ & $-0,007$ & $-0,008$ & $-0,017$ & $-0,024$ \\
\hline Coorte 1973-75 & & & & & & & 0,000 & $-0,001$ & $-0,001$ \\
\hline Coorte 1970-72 & & & & & & & 0,000 & $-0,001$ & $-0,001$ \\
\hline Coorte 1967-69 & & & & & & & 0,000 & $-0,001$ & $-0,001$ \\
\hline Coorte 1964-66 & & & & & & & 0,000 & 0,001 & 0,001 \\
\hline Coorte 1961-63 & & & & & & & 0,000 & $-0,002$ & $-0,002$ \\
\hline Coorte 1958-60 & & & & & & & 0,000 & $-0,001$ & $-0,001$ \\
\hline Coorte 1955-57 & & & & & & & 0,000 & $-0,002$ & $-0,002$ \\
\hline Coorte 1952-54 & & & & & & & 0,000 & $-0,004$ & $-0,004$ \\
\hline Coorte 1949-51 & & & & & & & 0,000 & $-0,001$ & $-0,001$ \\
\hline Coorte 1946-48 & & & & & & & 0,000 & $-0,001$ & $-0,001$ \\
\hline Coorte 1943-45 & & & & & & & 0,000 & $-0,001$ & $-0,001$ \\
\hline Coorte 1940-42 & & & & & & & 0,000 & $-0,001$ & $-0,001$ \\
\hline Coorte 1937-39 & & & & & & & 0,000 & 0,000 & $-0,001$ \\
\hline Coorte 1934-36 & & & & & & & 0,000 & 0,000 & 0,000 \\
\hline Diferença Total & 0,438 & 0,154 & 0,599 & 0,462 & 0,129 & 0,599 & 0,435 & 0,220 & 0,599 \\
\hline
\end{tabular}

Fonte: Elaboração própria, a partir dos microdados da PNAD, IBGE, 1987-1999. 
Tentando encontrar pistas de como o hiato salarial entre as mulheres brancas e negras é afetado pela distribuição salarial, a decomposição do diferencial em alguns percentis da distribuição é mostrada na Tabela 9. Estimativas dos coeficientes (em anexo) foram obtidas a partir de regressões quantílicas para o $10^{\circ}, 50^{\circ}$ (mediana) e $90^{\circ}$ percentis das distribuições salarial das mulheres brancas e negras. Um padrão visível é que o diferencial aumenta à medida que se sobe na hierarquia dos salários. Em todos os percentis, a parte explicada do hiato é muito mais forte do que a parte não explicada, e esta força torna-se ainda maior no décimo superior da distribuição. As diferenças não explicadas dos coeficientes, que determinam os retornos das características pessoais e ocupacionais, são similares entre os percentis.

\section{TABELA 9 - DECOMPOSIÇÃO DO HIATO SALARIAL POR RAÇA}

\begin{tabular}{|c|c|c|c|c|c|c|c|c|c|}
\hline & \multicolumn{3}{|c|}{$10^{\circ}$} & \multicolumn{3}{|c|}{$50^{\circ}$ (Mediana) } & \multicolumn{3}{|c|}{$90^{\circ}$} \\
\hline & Explic. & $\begin{array}{l}\text { Não } \\
\text { Exp. }\end{array}$ & Total & Explic. & $\begin{array}{l}\text { Não } \\
\text { Exp. }\end{array}$ & Total & Explic. & $\begin{array}{l}\text { Não } \\
\text { Exp. }\end{array}$ & Total \\
\hline Constante & & $-0,132$ & $-0,132$ & & $-0,311$ & $-0,311$ & & $-0,174$ & $-0,174$ \\
\hline 1996 & 0,000 & 0,003 & 0,003 & 0,005 & 0,002 & 0,006 & $-0,003$ & $-0,001$ & $-0,005$ \\
\hline 1993 & $-0,032$ & 0,013 & $-0,019$ & $-0,002$ & $-0,004$ & $-0,006$ & 0,001 & 0,002 & 0,002 \\
\hline 1990 & 0,005 & 0,022 & 0,027 & 0,000 & 0,007 & 0,007 & 0,000 & 0,010 & 0,010 \\
\hline 1987 & 0,001 & 0,013 & 0,014 & $-0,001$ & 0,003 & 0,003 & 0,003 & 0,000 & 0,003 \\
\hline Idade & $-0,030$ & 0,030 & 0,000 & $-0,044$ & 0,408 & 0,364 & 0,069 & 0,503 & 0,572 \\
\hline Idade $^{2}$ & 0,027 & 0,025 & 0,052 & 0,035 & $-0,147$ & $-0,112$ & $-0,045$ & $-0,184$ & $-0,230$ \\
\hline Estado Conjugal & 0,005 & 0,012 & 0,016 & 0,005 & 0,020 & 0,024 & 0,006 & 0,013 & 0,019 \\
\hline Filhos - 6 anos & 0,001 & 0,010 & 0,011 & 0,000 & 0,008 & 0,008 & 0,000 & 0,006 & 0,006 \\
\hline Chefe Domicílio & $-0,011$ & $-0,003$ & $-0,014$ & $-0,013$ & 0,010 & $-0,004$ & $-0,004$ & 0,008 & 0,004 \\
\hline Anos de Estudo & 0,140 & 0,050 & 0,189 & 0,233 & 0,108 & 0,341 & 0,274 & 0,110 & 0,384 \\
\hline Área Metropolit. & $-0,008$ & 0,006 & $-0,002$ & $-0,008$ & 0,021 & 0,013 & 0,022 & 0,009 & 0,032 \\
\hline Sudeste & 0,003 & 0,004 & 0,007 & 0,003 & 0,021 & 0,025 & 0,002 & 0,020 & 0,022 \\
\hline Nordeste & 0,138 & $-0,006$ & 0,132 & 0,075 & 0,008 & 0,082 & 0,046 & 0,041 & 0,086 \\
\hline Indústria Moderna & 0,003 & 0,000 & 0,003 & 0,009 & 0,000 & 0,008 & 0,001 & $-0,005$ & $-0,004$ \\
\hline Ind. Tradicional & 0,010 & 0,001 & 0,011 & 0,003 & 0,000 & 0,004 & 0,000 & $-0,004$ & $-0,004$ \\
\hline Serv. Distributivos & 0,004 & $-0,006$ & $-0,001$ & 0,003 & $-0,015$ & $-0,012$ & $-0,004$ & $-0,042$ & $-0,046$ \\
\hline Serv. Produtivos & 0,003 & 0,001 & 0,004 & 0,012 & 0,001 & 0,014 & 0,024 & $-0,020$ & 0,004 \\
\hline Serv. Pessoais & 0,006 & 0,000 & 0,007 & 0,006 & $-0,001$ & 0,005 & 0,001 & $-0,069$ & $-0,068$ \\
\hline Serv. Sociais & $-0,010$ & 0,009 & $-0,002$ & $-0,017$ & $-0,008$ & $-0,025$ & $-0,003$ & $-0,031$ & $-0,035$ \\
\hline Administr. Pública & 0,004 & 0,000 & 0,004 & 0,004 & 0,002 & 0,006 & 0,013 & $-0,006$ & 0,006 \\
\hline Ocup. Alto Nível & 0,006 & 0,001 & 0,007 & 0,052 & $-0,002$ & 0,050 & 0,203 & $-0,027$ & 0,177 \\
\hline Ocup. Médio Nível & 0,011 & 0,001 & 0,012 & 0,066 & 0,001 & 0,067 & $-0,034$ & $-0,004$ & $-0,037$ \\
\hline Trab. Doméstico & 0,002 & 0,002 & 0,003 & 0,011 & 0,004 & 0,015 & 0,010 & 0,000 & 0,010 \\
\hline Tempo Integral & $-0,040$ & $-0,006$ & $-0,046$ & $-0,043$ & 0,030 & $-0,013$ & $-0,023$ & 0,049 & 0,025 \\
\hline Setor Informal & 0,100 & 0,093 & 0,194 & 0,019 & 0,037 & 0,056 & $-0,015$ & 0,033 & 0,018 \\
\hline Ocup. Feminina & 0,002 & $-0,035$ & $-0,033$ & 0,017 & $-0,091$ & $-0,074$ & 0,064 & $-0,086$ & $-0,022$ \\
\hline Ocup. Integrada & 0,000 & 0,004 & 0,004 & $-0,001$ & $-0,003$ & $-0,004$ & $-0,004$ & $-0,009$ & $-0,013$ \\
\hline Total & 0,340 & 0,111 & 0,451 & 0,429 & 0,108 & 0,537 & 0,602 & 0,139 & 0,741 \\
\hline
\end{tabular}

Fonte: Elaboração própria, a partir dos microdados da PNAD, IBGE, 1987-1999. 


\section{COMENTÁRIOS CONCLUSIVOS}

Este artigo é uma tentativa de analisar as tendências da desigualdade salarial da força de trabalho feminina no Brasil, por raça, durante os anos 1980 e 1990, um período marcado por decrescentes níveis de fecundidade e crescentes níveis de educação e participação feminina na força de trabalho. A hipótese de que o hiato salarial por raça é determinado por diferenças individuais e ocupacionais foi confirmada, mas a hipótese de crescentes retornos de qualificação e demanda por trabalho qualificado, resultando em divergência do crescimento salarial entre trabalhadores com alta e baixa qualificação, não foi sustentada. O declínio da desigualdade dentro dos grupos raciais não resultou em um declínio da desigualdade salarial entre os grupos raciais.

Evidências de um status mais baixo no mercado de trabalho das mulheres negras em relação às brancas foram mostradas em várias dimensões. Isto constitui um fardo extra para as mulheres negras. A melhor posição econômica relativa das mulheres menos qualificadas (pela posição na distribuição salarial) levanta a possibilidade de que as tendências reflitam mudanças na composição da categoria menos educada mais do que mudanças em suas oportunidades ou comportamentos.

É desapontador ver a estagnação do hiato salarial por raça entre as mulheres nos últimos anos e não detectar qualquer indicação de futura reversão desta tendência, dado que as tendências das coortes não são significativamente diferentes, mesmo estando convergindo seus níveis educacionais. Todos os outros indicadores apontam para o fato de que diferentes padrões de características ocupacionais e diferentes retornos destas características por raça são determinantes neste fracasso das mulheres negras em converter os ganhos educacionais em ganhos salariais. Portanto, não é razoável inferir um progresso real em direção à igualdade racial. E assim é possível concluir como se inicia o artigo: no final dos anos 1990, mais de um século após a abolição formal da escravidão no Brasil, a situação das mulheres negras ainda se caracteriza por uma posição desfavorecida no mercado de trabalho. Dadas a longa persistência desta situação e a falta de evidências de uma reversão potencial, a discriminação deve ser considerada como um fator determinante dos diferenciais de raça no Brasil. Não somente a discriminação, mas as barreiras a uma inserção justa no mercado de trabalho.

\section{REFERÊNCIAS BIBLIOGRÁFICAS}

Altonji, J. G.; Blank, R. Race and gender in the labor market. In: Ashenfelter, O.; Card, D. (eds.), Handbook of labor economics. Amsterdan: North Holland, 1999. v. 3C, p. 3143-3257. 
Blau, F. D., Beller, A. H. Black-white earnings over the 1970s and 1980s: gender differences in trends. Review of Economics and Statistics, v. 74, n. 2, p. 276-286, 1992.

Blau, F. D. Trends in the well-being of American women, 1970-1995. Journal of Economic Literature, v. 36, n. 1, p. 112-165, 1998.

Deaton, A. Data and econometric tools for development analysis. In: Behrman, J.; Srinivasan, T. N. (eds.), Handbook of development economics. Amsterdam: Elsevier, 1995. v. 3A, p. 1785-1882.

The analysis of household surveys: microeconometric approach to development policy. Baltimore: Johns Hopkins University, 1997. 479 p.

Handcock, M. S.; Morris, M. Relative distribution methods in the social sciences. New York: Springer-Verlag, 1999. 265 p.

Hasenbalg, C. A. Discriminação e desigualdades raciais no Brasil. Rio de Janeiro: Graal, 1979. $302 \mathrm{p}$.

Hasenbalg, C. A.; Silva, N. V. Estrutura social, mobilidade e raça. Rio de Janeiro: Vértice, 1988. 200 p.

. Educação e diferenças raciais na mobilidade ocupacional no Brasil. In: ANPOCS. Encontro Anual, 22, 1998, Caxambu, MG. Anais. (Disponível em CD ROM).

Henriques, R. Desigualdade racial no Brasil: evolução das condições de vida na década de 90. Rio de Janeiro: IPEA, 2001. 49 p. (Texto para discussão; 807)

Juhn, C.; Murphy, K. M.; Pierce, B. Accounting for the slowdown in black-white wage convergence. In: Kosters, M. H. (ed.), Workers and their wages. Washington, D.C.: American Institute Enterprise, 1991. p. 107-143.

. Wage inequality and the rise in returns to skill. Journal of Political Economy, v. 101, n. 3, p. 410-441, 1993.

Leite, P. G. G. P.; Silva, D. B. N. Análise da situação ocupacional de crianças e adolescentes nas regiões Nordeste e Sudeste do Brasil utilizando a PNAD 1999. In: Encontro Nacional de Estudos Populacionais, 2002, Ouro Preto, MB. Anais. ABEP, 2002. (Disponível em CD-ROM).

Lovell, P. Racial inequality in the Brazilian labor market. 1989. Ph.D. Dissertation, University of Florida. Oliveira, A. M. H. C. Occupational gender segregation and effects on wages in Brazil. In: IUSSP GENERAL POPULATION CONFERENCE, 24, 2001, Salvador, BA. Proceedings. IUSSP, 2001. (Disponível em CD-ROM).

Oliveira, L. E. G.; Porcaro, R. M.; Costa, T. C. N. A. O lugar do negro na força de trabalho. Rio de Janeiro: IBGE, 1983. 86p.

Silva, N. V. O preço da cor: diferenciais raciais na distribuição de renda no Brasil. Pesquisa e Planejamento Econômico, v. 10, n. 1, p. 21-44, 1980. 
Silva, N. V.; Hasenbalg, C. A. Relações raciais no Brasil contemporâneo. Rio de Janeiro: Rio Fundo, 1992. 173 p.

Soares, S. S. D. O perfil da discriminação no mercado de trabalbo: homens negros, mulheres brancas e mulheres negras. Rio de Janeiro: IPEA, 2000. 26 p. (Texto para discussão; 769)

\section{ANEXO I - MÉDIAS DAS VARIÁVEIS}

\begin{tabular}{lrrlcc}
\hline & Brancas & Negras & & Brancas & Negras \\
\hline 1996 & 0,182 & 0,192 & Ocup. Alto Nível & 0,181 & 0,069 \\
1993 & 0,195 & 0,197 & Ocup. Médio Nível & 0,285 & 0,202 \\
1990 & 0,222 & 0,216 & Trab. Doméstico & 0,117 & 0,218 \\
1987 & 0,241 & 0,243 & Tempo Integral & 0,679 & 0,665 \\
Idade & 37,676 & 37,824 & Setor Informal & 0,401 & 0,523 \\
Idade & 1509,78 & 1523,35 & Ocup. Feminina & 0,687 & 0,762 \\
Estado Conjugal & 0,628 & 0,575 & Ocup. Integrada & 0,196 & 0,166 \\
Filhos - 6 anos & 0,284 & 0,318 & Coorte 1973-75 & 0,025 & 0,026 \\
Chefe Domicílio & 0,253 & 0,321 & Coorte 1970-72 & 0,048 & 0,049 \\
Anos de Estudo & 8,564 & 6,069 & Coorte 1967-69 & 0,070 & 0,075 \\
Área Metropolit. & 0,428 & 0,423 & Coorte 1964-66 & 0,102 & 0,101 \\
Sudeste & 0,576 & 0,429 & Coorte 1961-63 & 0,120 & 0,117 \\
Nordeste & 0,121 & 0,348 & Coorte 1958-60 & 0,117 & 0,115 \\
Indústria Moderna & 0,033 & 0,020 & Coorte 1955-57 & 0,111 & 0,107 \\
Ind. Tradicional & 0,082 & 0,067 & Coorte 1952-54 & 0,097 & 0,095 \\
Serv. Distributivos & 0,159 & 0,138 & Coorte 1949-51 & 0,084 & 0,081 \\
Serv. Produtivos & 0,099 & 0,055 & Coorte 1946-48 & 0,065 & 0,063 \\
Serv. Pessoais & 0,247 & 0,197 & Coorte 1943-45 & 0,049 & 0,050 \\
Serv. Sociais & 0,280 & 0,421 & Coorte 1940-42 & 0,039 & 0,042 \\
Administr. Pública & 0,065 & 0,055 & Coorte 1937-39 & 0,027 & 0,030 \\
Log. Salário/Hora & 0,753 & 0,154 & Coorte 1934-36 & 0,020 & 0,021 \\
\hline
\end{tabular}

Fonte: Elaboração própria, a partir dos microdados da PNAD, IBGE, 1987-1999. 
ANEXO 2 - COEFICIENTES DAS REGRESSÕES SALARIAIS POR RAÇA

\begin{tabular}{|c|c|c|c|c|c|c|c|c|c|c|c|c|}
\hline \multirow{3}{*}{ Intercepto } & \multicolumn{4}{|c|}{ Modelo 2} & \multicolumn{4}{|c|}{ Modelo 3} & \multicolumn{4}{|c|}{ Modelo 4} \\
\hline & \multicolumn{2}{|c|}{ Brancas } & \multicolumn{2}{|c|}{ Negras } & \multicolumn{2}{|c|}{ Brancas } & \multicolumn{2}{|c|}{ Negras } & \multicolumn{2}{|c|}{ Brancas } & \multicolumn{2}{|c|}{ Negras } \\
\hline & $-2,112$ & & $-1,926$ & & $-1,361$ & & $-1,183$ & & $-1,051$ & * & $-0,817$ & * \\
\hline 1996 & 0,104 & * & 0,107 & * & 0,083 & * & 0,083 & * & 0,072 & * & 0,073 & * \\
\hline 1993 & $-0,126$ & * & $-0,126$ & * & $-0,169$ & * & $-0,176$ & * & $-0,188$ & * & $-0,194$ & * \\
\hline 1990 & 0,068 & * & 0,021 & ** & $-0,010$ & & $-0,068$ & * & $-0,034$ & & $-0,093$ & * \\
\hline 1987 & 0,127 & * & 0,113 & * & 0,055 & * & 0,025 & * & 0,026 & & $-0,004$ & \\
\hline Idade & 0,055 & * & 0,052 & * & 0,054 & * & 0,047 & * & 0,038 & * & 0,028 & * \\
\hline Idade $^{2}$ & $-0,001$ & * & 0,000 & * & $-0,001$ & * & 0,000 & * & $-0,000$ & * & $-0,000$ & * \\
\hline Estado Conjugal & 0,237 & * & 0,221 & * & 0,212 & * & 0,193 & * & 0,213 & * & 0,193 & * \\
\hline Filhos menos 6 anos & 0,006 & & $-0,028$ & * & $-0,005$ & & $-0,032$ & * & $-0,004$ & * & $-0,032$ & * \\
\hline Chefe do Domicílio & 0,180 & * & 0,155 & * & 0,188 & * & 0,171 & * & 0,188 & * & 0,171 & * \\
\hline Anos de Estudo & 0,146 & * & 0,126 & * & 0,094 & * & 0,080 & * & 0,094 & * & 0,080 & * \\
\hline Área Metropolitana & 0,192 & * & 0,132 & * & 0,197 & * & 0,174 & * & 0,197 & * & 0,174 & * \\
\hline Sudeste & 0,024 & * & $-0,068$ & * & 0,021 & * & $-0,038$ & * & 0,021 & * & $-0,038$ & * \\
\hline Nordeste & $-0,307$ & * & $-0,356$ & * & $-0,348$ & * & $-0,390$ & * & $-0,347$ & * & $-0,390$ & * \\
\hline Indústria Moderna & & & & & 0,259 & * & 0,340 & * & 0,259 & * & 0,338 & * \\
\hline Indústria Tradicional & & & & & 0,104 & * & 0,125 & * & 0,104 & * & 0,124 & * \\
\hline Serv. Distributivos & & & & & 0,155 & * & 0,272 & * & 0,156 & * & 0,272 & * \\
\hline Serv. Produtivos & & & & & 0,309 & * & 0,326 & * & 0,309 & * & 0,325 & * \\
\hline Serv. Pessoais & & & & & 0,054 & * & 0,084 & * & 0,055 & * & 0,084 & * \\
\hline Serv. Sociais & & & & & 0,075 & * & 0,118 & * & 0,075 & * & 0,118 & * \\
\hline Administr. Pública & & & & & 0,276 & * & 0,250 & * & 0,276 & * & 0,250 & * \\
\hline Ocup. Alto Nível & & & & & 0,632 & * & 0,694 & * & 0,632 & * & 0,693 & * \\
\hline Ocup. Médio Nível & & & & & 0,303 & * & 0,289 & * & 0,303 & * & 0,289 & * \\
\hline Trabalho Doméstico & & & & & $-0,085$ & * & $-0,083$ & * & $-0,086$ & * & $-0,083$ & * \\
\hline Tempo Integral & & & & & $-0,354$ & * & $-0,403$ & * & $-0,354$ & * & $-0,403$ & * \\
\hline Setor Informal & & & & & $-0,096$ & * & $-0,188$ & * & $-0,096$ & * & $-0,187$ & * \\
\hline Ocupação Feminina & & & & & $-0,255$ & * & $-0,153$ & * & $-0,256$ & * & $-0,154$ & * \\
\hline Ocupação Integrada & & & & & $-0,048$ & * & $-0,011$ & & $-0,048$ & * & $-0,011$ & \\
\hline Coorte 1973-75 & & & & & & & & & $-0,048$ & & $-0,022$ & \\
\hline Coorte 1970-72 & & & & & & & & & $-0,022$ & & $-0,007$ & \\
\hline Coorte 1967-69 & & & & & & & & & 0,013 & & 0,003 & \\
\hline Coorte 1964-66 & & & & & & & & & 0,010 & & 0,027 & \\
\hline Coorte 1961-63 & & & & & & & & & 0,020 & & 0,030 & \\
\hline Coorte 1958-60 & & & & & & & & & 0,036 & & 0,056 & \\
\hline Coorte 1955-57 & & & & & & & & & 0,041 & & 0,087 & \\
\hline Coorte 1952-54 & & & & & & & & & 0,080 & & 0,090 & \\
\hline Coorte 1949-51 & & & & & & & & & 0,070 & & 0,088 & \\
\hline Coorte 1946-48 & & & & & & & & & 0,081 & & 0,102 & $* * *$ \\
\hline Coorte 1943-45 & & & & & & & & & 0,059 & & 0,071 & \\
\hline Coorte 1940-42 & & & & & & & & & 0,048 & & 0,063 & \\
\hline Coorte 1937-39 & & & & & & & & & 0,034 & & 0,038 & \\
\hline Coorte 1934-36 & & & & & & & & & 0,035 & & 0,036 & \\
\hline
\end{tabular}

Fonte: Elaboração própria, a partir dos microdados da PNAD, IBGE, 1987-1999. Nota: *** significante a $0,10,{ }^{*}$ significante a $0,05,{ }^{*}$ significante a 0,01 . 
ANEXO 3 - COEFICIENTES DAS REGRESSÕES SALARIAIS QUANTÍLICAS POR $R A C ̧ A$

\begin{tabular}{|c|c|c|c|c|c|c|c|c|c|c|c|c|}
\hline \multirow[b]{3}{*}{ Constante } & \multicolumn{4}{|c|}{$10^{\circ}$} & \multicolumn{4}{|c|}{$50^{\circ}$} & \multicolumn{4}{|c|}{$90^{\circ}$} \\
\hline & \multicolumn{2}{|c|}{ Brancas } & \multicolumn{2}{|c|}{ Negras } & \multicolumn{2}{|c|}{ Brancas } & \multicolumn{2}{|c|}{ Negras } & \multicolumn{2}{|c|}{ Brancas } & \multicolumn{2}{|c|}{ Negras } \\
\hline & $-1,666$ & * & $-1,533$ & * & $-1,381$ & 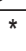 & $-1,070$ & * & $-0,778$ & 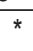 & $-0,603$ & * \\
\hline 1996 & 0,029 & * & 0,013 & & 0,066 & * & 0,057 & * & 0,125 & * & 0,131 & * \\
\hline 1993 & $-0,224$ & * & $-0,279$ & * & $-0,165$ & & $-0,145$ & * & $-0,111$ & * & $-0,122$ & \\
\hline 1990 & $-0,134$ & * & $-0,216$ & * & $-0,010$ & * & $-0,085$ & * & 0,067 & * & 0,020 & 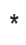 \\
\hline 1987 & $-0,013$ & & $-0,100$ & * & 0,053 & 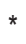 & 0,028 & * & 0,098 & * & 0,098 & 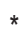 \\
\hline Idade & 0,041 & * & 0,041 & * & 0,053 & 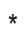 & 0,042 & $n^{n}$ & 0,062 & * & 0,048 & * \\
\hline Idade $^{2}$ & 0,000 & * & 0,000 & * & $-0,001$ & * & 0,000 & * & $-0,001$ & * & 0,000 & * \\
\hline Estado Conjugal & 0,175 & * & 0,155 & * & 0,204 & * & 0,171 & * & 0,221 & * & 0,200 & * \\
\hline Filhos menos 6 anos & $-0,012$ & & $-0,039$ & * & 0,000 & & $-0,024$ & * & 0,003 & & $-0,014$ & \\
\hline Chefe do Domicílio & 0,139 & * & 0,146 & * & 0,172 & * & 0,143 & * & 0,213 & * & 0,185 & 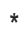 \\
\hline Anos de Estudo & 0,082 & * & 0,066 & * & 0,091 & * & 0,072 & * & 0,097 & * & 0,086 & * \\
\hline Área Metropolitana & 0,179 & * & 0,165 & * & 0,202 & * & 0,164 & * & 0,209 & * & 0,193 & 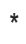 \\
\hline Sudeste & 0,017 & ** & $-0,001$ & & 0,032 & * & $-0,030$ & * & 0,015 & & $-0,046$ & * \\
\hline Nordeste & $-0,438$ & * & $-0,426$ & * & $-0,338$ & * & $-0,361$ & * & $-0,266$ & * & $-0,396$ & * \\
\hline Indústria Moderna & 0,283 & * & 0,234 & * & 0,278 & 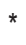 & 0,331 & * & 0,147 & * & 0,445 & * \\
\hline Indústria Tradicional & 0,151 & * & 0,131 & * & 0,129 & * & 0,128 & * & 0,029 & & 0,170 & * \\
\hline Serv. Distributivos & 0,080 & * & 0,136 & * & 0,139 & * & 0,234 & * & 0,148 & * & 0,415 & * \\
\hline Serv. Produtivos & 0,261 & * & 0,213 & * & 0,326 & * & 0,287 & * & 0,262 & * & 0,426 & * \\
\hline Serv. Pessoais & 0,126 & * & 0,117 & * & 0,064 & * & 0,072 & * & $-0,082$ & * & 0,105 & * \\
\hline Serv. Sociais & 0,055 & ** & 0,043 & & 0,079 & * & 0,095 & * & 0,031 & & 0,206 & * \\
\hline Administr. Pública & 0,216 & * & 0,192 & * & 0,270 & * & 0,225 & * & 0,316 & 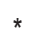 & 0,377 & . \\
\hline Ocup. Alto Nível & 0,527 & * & 0,480 & * & 0,663 & * & 0,762 & * & 0,745 & * & 0,869 & * \\
\hline Ocup. Médio Nível & 0,228 & * & 0,204 & & 0,319 & * & 0,313 & * & 0,399 & * & 0,407 & * \\
\hline Trabalho Doméstico & $-0,014$ & & $-0,018$ & * & $-0,086$ & * & $-0,105$ & * & $-0,178$ & * & $-0,171$ & 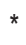 \\
\hline Tempo Integral & $-0,278$ & * & $-0,269$ & * & $-0,335$ & * & $-0,388$ & * & $-0,416$ & * & $-0,510$ & * \\
\hline Setor Informal & $-0,344$ & * & $-0,452$ & * & $-0,089$ & * & $-0,157$ & 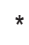 & 0,154 & * & 0,055 & 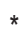 \\
\hline Ocupação Feminina & $-0,091$ & * & $-0,047$ & ** & $-0,244$ & * & $-0,128$ & * & $-0,406$ & . & $-0,284$ & * \\
\hline Ocupação Integrada & $-0,010$ & & $-0,035$ & *** & $-0,041$ & * & $-0,020$ & & $-0,056$ & * & $-0,003$ & \\
\hline
\end{tabular}

Fonte: Elaboração própria, a partir dos microdados da PNAD, IBGE, 1987-1999. Nota: *** significante a 0,10, ** significante a $0,05,{ }^{*}$ significante a 0,01 . 